The FASEB Journal express article 10.1096/fj.04-1581fje. Published online August 19, 2004.

\title{
Phosphatidylinositol 3-kinase and Akt effectors mediate insulin-like growth factor-I neuroprotection in dorsal root ganglia neurons
}

Gina M. Leinninger,* Carey Backus, ${ }^{\dagger}$ Michael D. Uhler, ${ }^{\ddagger}$ Stephen I. Lentz, ${ }^{\S}$ and Eva L. Feldman ${ }^{\dagger}$

*Neuroscience Program, University of Michigan, Ann Arbor, Michigan; ${ }^{\dagger}$ Department of Neurology, University of Michigan, Ann Arbor, Michigan; ${ }^{\ddagger}$ Department of Biological Chemistry and the Mental Health Research Institute, Ann Arbor, Michigan; and ${ }^{\S}$ MDRTC Morphology and Image Analysis Core, University of Michigan, Ann Arbor, Michigan

Corresponding author: Eva L. Feldman, University of Michigan, Department of Neurology 4414 Kresge III, 200 Zina Pitcher Place Ann Arbor, MI 48109. E-mail: efeldman@umich.edu

\section{ABSTRACT}

Insulin-like growth factor-I (IGF-I) protects neurons of the peripheral nervous system from apoptosis, but the underlying signaling pathways are not well understood. We studied IGF-I mediated signaling in embryonic dorsal root ganglia (DRG) neurons. DRG neurons express IGFI receptors (IGF-IR), and IGF-I activates the phosphatidylinositol 3-kinase (PI3K)/Akt pathway. High glucose exposure induces apoptosis, which is inhibited by IGF-I through the PI3K/Akt pathway. IGF-I stimulation of the PI3K/Akt pathway phosphorylates three known Akt effectors: the survival transcription factor cyclic AMP response element binding protein (CREB) and the

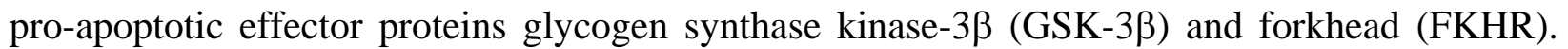
IGF-I regulates survival at the nuclear level through accumulation of phospho-Akt in DRG neuronal nuclei, increased CREB-mediated transcription, and nuclear exclusion of FKHR. High glucose increases expression of the pro-apoptotic $\mathrm{Bcl}$ protein Bim (a transcriptional target of FKHR). However, IGF-I does not regulate Bim or anti-apoptotic Bcl-xL protein expression levels, which suggests that IGF-I neuroprotection is not through regulation of their expression. High glucose also induces loss of the initiator caspase- 9 and increases caspase- 3 cleavage, effects blocked by IGF-I. These data suggest that IGF-I prevents apoptosis in DRG neurons by regulating PI3K/Akt pathway effectors, including GSK-3 $\beta$, CREB, and FKHR, and by blocking caspase activation.

Key words: insulin-like growth factor $\bullet$ dorsal root ganglia neurons $\bullet$ apoptosis $\bullet$ glucose $\bullet$ CREB - FKHR

I nsulin-like growth factor-I (IGF-I) is a potent growth factor required during development. IGF-I is critical for proper peripheral nervous system (PNS) development, demonstrated by IGF-I deficient mice, which have abnormal PNS anatomy and physiology (1). Further, functional IGF-I receptor (IGF-IR) expression is critical for survival, as homozygous IGF-IR deficient mice are embryonic lethal (1). Although multiple neurotrophic factors support either 
sensory or motor neurons of the PNS, IGF-I is the only neurotrophic factor that supports both sensory and motor neuron regeneration (2). IGF-I rescues motor neurons from apoptosis following axotomy or spinal transection (3). IGF-I also protects dorsal root ganglion (DRG) sensory neurons from apoptosis-induced by nerve growth factor withdrawal and promotes neurite extension $(4,5)$. Additionally, IGF-I stimulates regeneration in injured peripheral nerves, restoring function (6). Thus, IGF-I is a critical factor for the development, maintenance, and regeneration of PNS neurons.

Although IGF-I clearly mediates neuroprotective responses, the intracellular signaling mechanisms underlying this protection remain elusive. The bulk of information about neuronal IGF-I survival signaling is from transformed cell lines (e.g., SH-SY5Y neuroblastoma and PC12 cell lines; 7, 8). However, due to the immortalization process, it is unlikely that IGF-I:IGF-IR signaling in transformed cell lines is a true representation of IGF-I:IGF-IR signaling in primary neurons. In primary hippocampal and cerebellar granule cells IGF-I activates the phosphatidylinositol 3-kinase (PI3K)/Akt kinase pathway, a common survival signaling pathway $(9,10)$. IGF-I inhibits apoptosis in cerebellar granule cells by preventing activation of the forkhead family member, FKHRL1, thereby inhibiting transcription of the pro-apoptotic protein, Bim (11). However, the signaling mechanisms underlying IGF-I:IGF-IR protection in primary PNS neurons remain unknown.

To better understand IGF-I mediated survival signaling in primary PNS neurons, we studied effects of IGF-I on cultured DRG sensory neurons. DRG neurons undergo apoptosis when exposed to $45 \mathrm{mM}$ glucose, exhibiting mitochondrial dysfunction and caspase activation (12). IGF-I inhibits glucose-induced apoptosis in DRG neurons (13). We used this model to investigate both IGF-I mediated rescue and IGF-I signaling cascades in DRG neurons. We find that IGF-I:IGF-IR activates the PI3K/Akt pathway and phosphorylates three known Akt effectors: the survival transcription factor cyclic AMP response element binding protein (CREB)

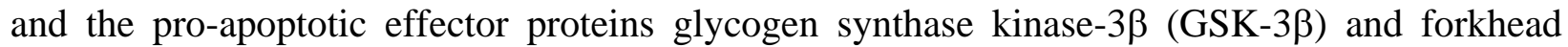
(FKHR). IGF-I blocks apoptosis in DRG neurons by modulating these effectors and preventing caspase activation. In contrast, glucose exposure increases expression of the pro-apoptotic protein Bim, which IGF-I does not inhibit. Collectively, these data suggest IGF-I mediates DRG neuronal survival by multiple signaling cascades and support the idea that IGF-I may be a potent therapy in PNS disorders.

\section{MATERIALS AND METHODS}

\section{Materials}

Recombinant human IGF-I was kindly provided by Cephalon, Inc. (Westchester, PA). NGF depletion studies were accomplished using an anti-NGF antibody from R\&D Systems (Minneapolis, MN). The MEK/MAPK and PI3K pathways were inhibited through treatment with PD98059 and LY294003 reagents, respectively, from Calbiochem (San Diego, CA). Collagen, selenium, hydrocortisone, $\beta$-estradiol, 5-fluoro-2'-deoxyuridine (FUDR), bovine serum albumin (BSA), L-glutamine, and D-glucose were obtained from Sigma (St. Louis, MO). Media reagents, including neurobasal media, penicillin/streptomycin/neomycin, and B27 supplement, were

purchased from Gibco BRL (Carlsbad, CA). Transferin, included in NB+ culture media, was 
from MP Biomedicals (Irvine, CA). For certain analyses, sample plates were made of ACLAR plastic purchased from Electron Microscopy Sciences (Fort Washington, PA).

\section{Cell culture}

DRG neurons were isolated from E15 Sprague Dawley rat embryos. Isolated DRG neurons were plated onto collagen-coated plastic dishes in $\mathrm{NB}+$ media supplemented with B27 (without antioxidants) and $1.4 \mathrm{mM}$ L-glutamine. $\mathrm{NB}+$ media is composed of neurobasal media $+30 \mathrm{nM}$ selenium, $10 \mathrm{nM}$ hydrocortisone, $10 \mu \mathrm{g} / \mathrm{mL}$ transferrin, $10 \mathrm{nM} \beta$-estradiol, $10 \mathrm{ng} / \mathrm{mL} 2.5 \mathrm{~S}$ nerve growth factor (NGF), $30 \mu \mathrm{M}$ FUDR, and penicillin/streptomycin/neomycin (5000 U/5 mg/10 mg per $\mathrm{mL}$, respectively). After $24 \mathrm{~h}$, neurons were fed with $\mathrm{NB}^{+}$, at a ratio of 2-3 times the volume of plating media. DRG neurons were used for experiments after 3 days in culture; at this point, the cultures are composed of $>95 \%$ neurons. NB+ media contains $25 \mathrm{mM}$ glucose and is hereby referred to as "control" in the text. We have previously shown that $25-30 \mathrm{mM}$ glucose is optimal for DRG neuron survival and neurite outgrowth, reflecting the high metabolic rate of neurons compared with non-neuronal cells (13). Although $25-30 \mathrm{mM}$ glucose is high compared with non-neuronal cultures, it is comparable with concentrations used in other central and peripheral neuronal cultures (14). DRG neurons require at least $45 \mathrm{mM}$ glucose to induce apoptosis (12); thus, high-glucose treatment media consists of control media plus $20 \mathrm{mM}$ additional glucose. Glucose at $45 \mathrm{mM}$ concentration is much higher than glucose concentrations in vivo during diabetes or in other hyperglycemic in vitro models. However, $45 \mathrm{mM}$ glucose treatment represents merely a 1.8-fold increase in glucose concentration above control, less than the threefold increase used for studying glucose-induced apoptosis in pancreatic $\beta$ islets (15) or the greater-than-threefold increase in mean blood glucose levels evidenced in rats made diabetic by streptozotocin injection (13). Glucose treatment ( $45 \mathrm{mM}$; 1.8 -fold above control) is similar to the $\geq 1$.4-fold increase in blood glucose concentration in a person diagnosed as diabetic (16). Thus, the relative concentration used in these studies is consistent with other models of hyperglycemia and human diabetes.

\section{TUNEL staining}

DRG neurons were plated on plastic ACLAR dishes, at a concentration of 500 neurons per dish. After treatment for $24 \mathrm{~h}$, cells were fixed with $4 \%$ paraformaldehyde and rinsed 3 times with PBS. Fixed cells were permeabilized in $0.1 \%$ Triton-X-100 and labeled for TUNEL-positive nuclei using the ApopTag Peroxidase in situ Apoptosis Detection Kit from Chemicon (Temecula, CA). The cells were counterstained with hematoxylin (Sigma) to label non-TUNEL positive cells, then were mounted on slides and examined using a Nikon Eclipse TS-100 inverted phase microscope. As assessed using a $\times 20$ microscope objective, each field contained $\sim 10-20$ DRG neurons. Samples were blinded prior to counting, and sample identities were not revealed until count completion. Counts were determined as follows: For each sample, 10 random neurons per field in 10 randomly selected fields were counted, yielding the total number of TUNEL positive cells out of 100 counted cells. This was reported as the percentage of TUNEL-positive cells. Only cells that could be morphologically identified as neurons (i.e., cells with characteristic round DRG neuronal cell bodies and intact neuronal processes) were counted. This counting method surveyed $\sim 20 \%$ of the total DRG neuron population per sample plate, consistent with population surveys performed by other groups. The experiment was repeated 4 times for all samples except glucose + IGF-I + PD98059, which was repeated 3 times. Graphed 
data represent the average of the percentage of TUNEL positive for the experimental sets. Error bars represent standard error of the mean (SEM). Significance was determined by students' $t$-test, using a two-tailed test and assuming equal variances.

\section{Immunocytochemistry}

DRG neurons on ACLAR dishes or glass coverslips were treated with experimental media and fixed with $4 \%$ paraformaldehyde. Cells were then permeabilized with $0.1 \%$ Triton-X-100, followed by blocking in 0.1 or $5 \%$ BSA/goat serum in PBS (pH 7.4), as specified by antibody technical sheets. Primary antibodies were added for $12-16 \mathrm{~h}$ at $4^{\circ} \mathrm{C}$. In the experiment probing IGF-I and TrkA receptor expression, the antibody against IGF-IR (Upstate Biotechnology, Lake Placid, NY) was used at a dilution of 1:250 and the antibody against TrkA (BD PharMingen, San Diego, CA) at 1:1000. Investigations of Akt and FKHR localization used antibodies against phosphorylated Akt (Ser473, IHC specific) and FKHR (Ser256) from Cell Signaling Technology (Beverly, MA), at 1:100 dilutions. After primary antibody labeling, cells were rinsed with PBS and exposed to the species appropriate AlexaFluor 488 and/or AlexaFluor 594 fluorescent secondary antibody conjugates (Molecular Probes, Eugene, $\mathrm{OH}$ ), diluted 1:500 in 0.1\% Triton$\mathrm{X}-100$, for $1 \mathrm{~h}$ at room temperature. Cells were then labeled with $0.01 \%$ Hoechst 33342 dye (Molecular Probes), rinsed with PBS, and mounted on glass slides using the ProLong Antifade kit (Molecular Probes). For the TrkA/IGF-IR expression experiment and the phospho-FKHR localization experiment, fluorescent cells were visualized using a $\times 40$ objective on a Nikon Diaphot inverted stage microscope outfitted with rhodamine, FITC, and UV filters. Images were captured using Compix Simple PCI software (Compix Inc. Imaging Systems, Cranberry Township, PA) and a Hamamatsu ORCA extended range digital CCD camera (C4742-95-12ER). For each TrkA/IGF-IR and phospho-FKHR sample, images from three random fields were collected. Experiments were repeated in triplicate so that images herein are representative of nine separate fields across three sample sets. Analysis of phospho-Akt localization was performed with an Olympus FluoView 500 laser scanning confocal microscope. Fluorophores were excited with either a $405 \mathrm{~nm}$ blue diode laser or a green helium neon (543 nm) laser. Samples were scanned on an Olympus IX-71 inverted microscope using a $\times 60$ water-immersion objective and magnified three times with FluoView software. Three random fields were selected for each sample, and a z-series was collected for each field. The z-series spanned $\sim 5 \mu \mathrm{m}$ in order to sample through the entire nuclear region. The image representing the widest extent of the nucleus from each z-series (i.e., the middle "slice" of the nucleus) was selected for analysis. Experiments were repeated in triplicate so that images in photomicrographs are representative of nine separate fields across 3 sample sets.

\section{Immunoblotting}

DRG neurons were cultured in $60 \times 15 \mathrm{~mm}$ tissue culture plates (BD Falcon, San Diego, CA). After treatment, cell lysates were collected in lysis buffer (20 mM Tris, pH 7.2; $1.16 \mathrm{M} \mathrm{NaCl;} 1$ mM EDTA; 1 mM EGTA; 1\% Triton X-100; 1 mM phenylmethylsulfonylfluoride; 0.1 trypsin inhibitory units of aprotinin/mL; $10 \mu \mathrm{g} / \mathrm{mL}$ leupeptin; and $1 \mathrm{mM} \mathrm{Na} \mathrm{VO}_{4}$ ) and concentrated using Centriprep filter columns (Millipore, Billerican, MA). The protein concentration of each lysate was determined by Lowry Assay, using Bio Rad $\mathrm{D}_{\mathrm{c}}$ protein assay reagents (Bio Rad, Hercules CA). Equivalent amounts of lysate $(40-60 \mu \mathrm{g})$ were diluted to a final concentration of $1^{\prime}$ with 10X SDS-PAGE sample buffer, boiled for 5 min and separated on 11-15.0\% SDS-PAGE 
gels. Gel components were transferred to BioTrace PVDF membranes (Pall Co., Ann Arbor, MI), followed by blocking in Tris buffered saline, $\mathrm{pH} 8.0+0.1 \%$ Tween-20 (TBS-T), and either $5 \%$ nonfat dried milk or 1\% BSA (depending on primary antibodies to be used) for $2 \mathrm{~h}$ at room temperature. Primary antibodies were diluted in appropriate blocking solution and incubated with membranes overnight at $4^{\circ} \mathrm{C}$. Excess primary antibody was removed by rinsing with TBS-T, followed by $1 \mathrm{~h}$ incubation with the species-appropriate horseradish peroxidase-conjugated secondary antibodies (diluted 1:2000 in blocking solution) at room temperature. Membranes were subsequently rinsed with TBS-T and exposed to LumiGlo enhanced chemiluminescence reagents (Cell Signaling). In some experiments, membranes were stripped for 15 min in $0.5 \mathrm{M}$ Tris buffer ( $\mathrm{pH} 6.8$ ), 2\% SDS, and $0.1 \mathrm{M} \mathrm{1,4}$ Dithio-DL-threitol at $70^{\circ} \mathrm{C}$, then blocked and reprobed with antibodies as described above. Immunoblots shown are representative of at least three independent experiments. Each blot was probed with an antibody against GAPDH at a dilution of 1:1000 (Chemicon Inc.) to verify equivalent protein loading between samples. Primary antibodies against cleaved caspase-3, rat caspase-9, Akt, phospho-Akt (Ser473), p44/p42 MAP kinase, phospho-p44/42 MAP kinase (Thr202/Tyr204), phospho-FKHR (Ser256), and phospho-CREB (Ser133) from Cell Signaling Technology were used at 1:1000 dilutions. Antibodies against Bcl-xL and the carboxy terminus of Bim (Santa Cruz Biotechnology, Santa Cruz, CA) were used at 1:160 dilutions.

\section{Densitometry of immunoblots}

Digital scans of immunoblot films were collected at a resolution of $300 \mathrm{dpi}$. Densitometry was performed by measuring pixel density in a defined region of each band using NIH Image 1.63 for Mac. Background pixel density was subtracted from band pixel density to determine a corrected pixel density for each sample. Each corrected pixel density value was divided by the control sample to determine a relative fold change value. (For Fig. $8 B$, the glucose sample served as the "control" value and was used as the divider). The fold change values for each experiment were averaged, and these averages are represented in graph format. Error bars represent the SEM. Significance of fold changes between samples was assessed by one-way ANOVA with Tukey's or Dunnett's post tests, using GraphPad InStat version 3.0a for Macintosh, (GraphPad Software, San Diego, CA).

\section{Preparation of transfection complexes}

The adenoviral penton protein was essentially prepared as described previously (17). Several plasmids were used for transfection, including pDsRed2-C1, pTAL-Luc, and pCRE-Luc plasmids from Clontech (Palo Alto, CA) and the pRL-SV40 plasmid from Promega (Madison, WI). Transfection complexes contained $100 \mathrm{ng}$ of pDsRed2-C1, $100 \mathrm{ng}$ of pRL-SV40, and 800 ng of pTAL-Luc or pCRE-Luc with $60 \mu \mathrm{g}$ of penton protein, $3 \mu \mathrm{g}$ of lipofectamine 2000 and $2.5 \%(\mathrm{w} / \mathrm{v})$ sucrose in a total volume of $12 \mu \mathrm{l}$ that was spread on the bottom of an 8-well collagen-treated slide chamber (Becton Dickenson Discovery Labware, Treyburn, CA).

\section{Preparation of DRG neurons for transfection}

DRG neurons were isolated as described above and plated on transfection slides in NB+ supplemented with B27 (without antioxidants) and $1.4 \mathrm{mM} \mathrm{L-glutamine.} \mathrm{Cells}\left(1 \times 10^{5}\right)$ were plated per well. After $24 \mathrm{~h}$ in culture, cells were exposed to treatment media for $24 \mathrm{~h}$ and then 
analyzed for luciferase levels (as described below). Treatment medias were composed of NB+ supplemented with B27 and IGF-I, high glucose, or LY294002 inhibitor, as described in the Results section.

\section{Luciferase determinations}

Renilla and firefly luciferase assays were performed using the Dual-Luciferase Reporter Assay System (Promega). DRG neuronal extracts were prepared in a total volume of $100 \mu \mathrm{l}$ kit lysis buffer, and $20 \mu \mathrm{l}$ was used per assay. Each condition (control, IGF-I, glucose-treated) was assayed twice in three separate experiments, such that each $n$ in the text (total $n=6$ ) represents a separate transfected well. Luciferase activity values were determined in triplicate for each transfected sample well. Neuronal transfection efficiency varied between $30-50 \%$ for the 3 experiments as determined by fluorescence microscopy examination of DsRed expression.

\section{RESULTS}

\section{DRG neurons have IGF-I and TrkA receptors}

As a first step, we confirmed the presence of IGF-IR in DRG neurons. DRG neurons are cultured in media containing high levels of NGF, sufficient to saturate the high-affinity NGF receptor, TrkA. Therefore, we studied both IGF-I:IGF-IR mediated signaling and the effect of NGF-TrkA on IGF-I signaling in DRG neurons. Neurons were analyzed by fluorescent immunocytochemistry for TrkA (red) and IGF-IR (green) expression (Fig. 1). Nuclei were stained with Hoechst 33342 dye (blue). TrkA is expressed throughout the extra-nuclear region of cell bodies and in the neuronal processes of many cultured DRG neurons (Fig. 1A). Expression is diffuse throughout the cell bodies but has a punctate staining pattern in neuronal processes. IGFIR is also expressed in the extra-nuclear cell body region and in the neurites of DRG neurons (Fig. 1B). TrkA receptor (red) and IGF-IR (green) are both restricted from nuclei (blue, Fig. 1C). Most neuronal cell bodies express both receptors, resulting in the yellow cell bodies in the overlay (Fig. 1C). However, the overlay image reveals that some neuronal processes dominantly express either TrkA (note arrowheads) or IGF-IR (note arrows) (Fig. 1C), reflecting the in vivo subtypes of DRG neurons (18). Although the antibody used to detect IGF-IR may also label IGFIR/insulin-receptor hybrids, hybrid receptors are known to functionally behave like IGF-IRs (19). Thus, the presence of hybrid receptors would not compromise IGF-I signaling.

\section{IGF-I induces phosphorylation of Akt}

Both IGF-I and NGF can activate the MEK/ERK pathway, which is implicated in survival signaling $(20,21)$, and the PI3K pathway, which activates Akt (or Protein Kinase B), also implicated in survival signaling $(10,22)$. To determine IGF-I:IGF-IR activation of the ERK/MAPK and PI3K/Akt pathways in DRG neurons, we added 10 nM IGF-I to DRG for 0, 30, or $60 \mathrm{~min}$ and assayed for phosphorylated Akt (pAkt) and phosphorylated ERK (pERK) by immunoblotting (Fig. 2A). The $10 \mathrm{nM}$ dose of IGF-I was chosen because it prevents apoptosis in DRG neurons subjected to NGF-withdrawal and is sufficient to activate the IGF-IR but not the insulin receptor $(4,23)$. After addition of $10 \mathrm{nM}$ IGF-I, ERK phosphorylation remains constant. In contrast, Akt phosphorylation increases with addition of IGF-I and remains activated throughout the time course. GAPDH bands are equal between samples, indicating that 
phosphorylation differences are not attributable to uneven protein loading. Fold changes of pAkt and pERK expression are shown in Fig. 2C. Expression of pERK does not change in response to IGF-I $(P>0.05)$. However, fold increases in phosphorylated Akt are significant after IGF-I treatment for $30 \mathrm{~min}(P<0.05)$ and $60 \mathrm{~min}(P<0.01)$.

The presence of saturating NGF levels in culture media could mask IGF-I effects on both the ERK/MAPK and Akt proteins. We therefore deprived DRG neurons of NGF for $3 \mathrm{~h}$ and simultaneously treated with anti-NGF antibodies to deplete cells of any residual NGF. NGFdeprived DRG neurons were then treated with $10 \mathrm{nM}$ IGF-I for 0 , 30, or 60 min (Fig. 2B). NGFdeprived DRG neurons exhibit no increase in ERK phosphorylation (pERK) throughout the time course. However, as in DRG neurons exposed to NGF, the NGF-deprived DRG neurons exhibit increased Akt phosphorylation (pAkt) with IGF-I treatment (Fig. 2B). These phosphoprotein differences are not due to unequal protein loading, demonstrated by the corresponding GAPDH immunoblot. As in the case when NGF was present, total-fold pERK expression does not alter with IGF-I treatment (Fig. 2D, $P>0.05$ ). However, there is a significant fold increase in pAkt expression with 30 or 60 min of IGF-I treatment (Fig. 2D, $P<0.01$ ). These data suggest that the presence of NGF does not prevent DRG neurons from responding to IGF-I. Interestingly, depletion of NGF from DRG neuronal cultures elicits a larger-fold increase in pAkt than that of DRG neurons in the presence of NGF. NGF may blunt the neuron's ability to respond to IGF-I through the PI3K/Akt pathway, although it does not prevent it. Thus, IGF-I:IGF-IR activates the Akt pathway but has little effect on the ERK/MAPK pathway in embryonic DRG neurons.

\section{IGF-I inhibits glucose-induced apoptosis in DRG neurons via the PI3K pathway}

We have previously reported that rat DRG neurons survive optimally in media containing 25-30 $\mathrm{mM}$ glucose, but higher glucose concentrations induce apoptosis (12). In addition, we have shown that IGF-I blocks glucose-induced apoptosis in DRG neurons (13) but had not examined the intracellular signaling pathways mediating IGF-I neuroprotection. Therefore, we next asked whether increased IGF-I activation of the PI3K/Akt pathway was sufficient to block apoptosis in DRG neurons. Of the DRG neurons grown in control media (25 mM glucose), 23.5\% undergo apoptosis, which was measured by TUNEL staining and represented the basal level of apoptotic death after three days in culture. Treatment of DRG neurons with high glucose ( $45 \mathrm{mM}$ total) for $24 \mathrm{~h}$ increases apoptosis compared with treatment with control media (Fig. 3; G $=55.3 \pm 2.0 \%$ TUNEL-positive cells, $\mathrm{C}=23.5 \pm 2.4 \%$ TUNEL positive cells, $P<0.01$ ). In contrast, $10 \mathrm{nM}$ IGF-I inhibits glucose-mediated apoptosis (Fig. 3; G+I $=24.5 \pm 4.7 \%$ TUNEL positive, $P<0.01$ ). Addition of the PD98059 MEK pathway inhibitor results in slightly lower levels of apoptosis than with glucose and IGF-I alone (Fig. 3; G+I+PD $=18 \pm 3.8 \%$ TUNEL positive vs. $\mathrm{C}=$ $23.5 \pm 2.4 \%$ TUNEL-positive cells, $P<0.01$ ). However, addition of the PI3K inhibitor, LY294002, blocks IGF-I-mediated protection, returning apoptotic levels to those seen in cells treated with glucose alone (Fig. 3; $\mathrm{G}+\mathrm{I}+\mathrm{LY}=55.5 \pm 2.0 \%$ TUNEL positive vs. $\mathrm{G}=55.3 \pm 2.0 \%$ TUNELpositive cells, $P<0.01$ ). The DMSO solvent without inhibitor has no effect on apoptosis (Fig. 3; $\mathrm{G}+\mathrm{I}+\mathrm{DMSO}=24 \pm 4.9 \%$ TUNEL-positive cells vs. $\mathrm{G}+\mathrm{I}=24.5 \pm 4.7 \%$ TUNEL-positive cells).

\section{IGF-I activates cytosolic and nuclear proteins important for survival of DRG neurons}

Our results demonstrating IGF-I rescue through the PI3K/Akt pathway imply that Akt downstream effectors may mediate neuroprotection. Akt regulates many proteins via 


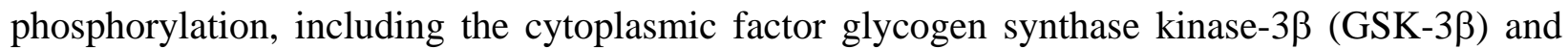
the transcription factors cyclic AMP response element binding protein (CREB) and forkhead (FKHR) (24). To better understand how these proteins might be regulated by IGF-I through the PI3K/Akt pathway, we treated DRG neurons for 0 (Control), 15 or 30 min with $10 \mathrm{nM} \mathrm{IGF-I} \pm$ $0.1 \%$ DMSO or $20 \mu \mathrm{M}$ LY294002 and analyzed for activation of GSK-3 $\beta$, CREB, and FKHR via immunoblotting (Fig. 4A). IGF-I increases Akt phosphorylation (pAkt) after 15 min of treatment in control and high-glucose media, and this phosphorylation is sustained with 30 min of IGF-I treatment. Addition of DMSO vehicle does not affect IGF-I mediated phosphorylation of Akt, but the PI3K inhibitor LY294002 inhibits Akt phosphorylation. Thus, PI3K pathway inhibition effectively prevents Akt activation. Densitometry confirms that IGF-I induced changes in fold activation of Akt are significant at 15 and 30 min (data not shown; $P<0.05$ ) and that LY294002 inhibits Akt phosphorylation compared with DMSO vehicle alone (data not shown, $P<0.01)$. Similar to Akt, GSK-3 $\beta$ phosphorylation increases after 15 min of IGF-I treatment $(P<0.05)$. GSK-3 $\beta$ phosphorylation is also increased by $15 \mathrm{~min}$ of IGF-I treatment in highglucose media. Inhibition of the PI3K/Akt pathway with LY294002 reduces GSK-3 $\beta$ phosphorylation to control levels (Fig. 4A, $P<0.05$ ). Densitometric analysis of GSK-3 $\beta$ phosphorylation (Fig. 4B) indicates that IGF-I induced phosphorylation changes are significant and that the variation between samples is not due to chance $(P<0.05)$.

FKHR, a member of the FOXO subfamily of Forkhead transcription factors, is a target of IGF-I (9). The FOXO proteins contain 3 Akt phosphorylation sites (Thr24, Ser256, and Ser319). Aktmediated phosphorylation of FKHR inhibits the transcriptional abilities of FKHR in the nucleus (25). In DRG neurons, IGF-I induces FKHR phosphorylation after 15 and 30 min of treatment (Fig. 4A). Blocking IGF-I signal transduction through the PI3K/Akt pathway with LY294002 inhibits FKHR phosphorylation. Densitometric analysis (Fig. 4B) indicates that IGF-I induced changes in FKHR phosphorylation at 15 and 30 min are significant compared with control levels $(P<0.05)$ and that LY294002 inhibits FKHR phosphorylation compared with DMSO vehicle alone $(P<0.05)$. Interestingly, addition of IGF-I in conjunction with high glucose for 15 min does produce FKHR phosphorylation, but at a reduced level compared with that seen with IGF-I in control media.

The transcription factor CREB is also regulated by IGF-I via the PI3K/Akt pathway. CREB phosphorylation increases after 15 min of IGF-I treatment in control $(P<0.001)$ and high glucose media $(P<0.01)$, but phosphorylation decreases after $30 \mathrm{~min}$ (Fig. 4A). CREB phosphorylation is increased in the presence of IGF-I and DMSO vehicle but is inhibited by LY294002 $(P<0.05)$.

CREB binds to DNA sequences containing the cyclic AMP response element (CRE; 26). We therefore examined glucose and IGF-I effects on CREB transcription by expressing plasmids containing either a control promoter lacking a CRE (pTAL) or a promoter containing a CRE (pCRE) conjugated to a firefly luciferase reporter gene (Fig. 4C). DRG neurons were also transfected with a transfection control plasmid containing the SV40 promoter directing expression of renilla luciferase. DNA binding was assessed by measuring firefly luciferase fluorescence, and levels were normalized between samples by using the renilla luciferase fluorescence. The data are reported as fold change of luciferase fluorescence in treated samples over control samples. DRG neurons expressing pTAL do not exhibit a change in luciferase fluorescence, demonstrating a lack of nonspecific reporter activation. However, DRG neurons 
treated with control media + $10 \mathrm{nM}$ IGF-I for 24 h exhibit a 2.8-fold increase in CRE-dependent reporter activity compared with DRG neurons in control media alone. Addition of high glucose for $24 \mathrm{~h}$ only slightly increased CRE binding over control levels. However, addition of high glucose $+10 \mathrm{nM}$ IGF-I for $24 \mathrm{~h}$ induced a 2.7-fold increase in CRE binding compared with control (Fig. 4C, $P<0.005$ ). As a control, LY294002 was added to both control and control +10 nM IGF-I media; both 24 h treatments depressed CRE binding slightly below control levels. This finding suggests a slight basal level of CREB-mediated transcription in DRG neurons but that IGF-I stimulation of the PI3K/Akt pathway is necessary for significant CREB-induced transcription.

\section{IGF-I causes phosphorylated Akt to translocate from the cytosol to the nucleus}

Our results demonstrate that IGF-I mediated activation of Akt induces phosphorylation of cytoplasmic proteins (GSK-3 $\beta$ ) and transcription factors (CREB, FKHR). Two possibilities exist: Phospho-Akt may activate nuclear proteins through initially affecting cytosolic proteins or that phospho-Akt may itself translocate into the nucleus to interact with nuclear proteins directly. We therefore examined the localization of phosphorylated Akt (Ser473) by immunocytochemistry and confocal microscopy in control DRG neurons and DRG neurons treated with $10 \mathrm{nM}$ IGF-I for 15 and $60 \mathrm{~min}$ (Fig. 5A). Phospho-Akt is visualized in red and nuclei are blue. Control-treated DRG neurons express phosphorylated Akt within cell bodies but not within nuclei (Fig. 5A). Addition of IGF-I for 15 min induces translocation of some phosphoAkt into the nucleus, represented by the punctate pink staining that results from an overlap of red phospho-Akt and blue nuclear labels (Fig. 5A, arrow). However, after 60 min of IGF-I treatment, a large amount of phosphorylated Akt within many DRG nuclei was found, evidenced by the intense pink staining (Fig. 5A). Although phospho-Akt is still present in the cell body, we found an increased nuclear localization compared with that seen in control DRG neurons. Samples pretreated with $20 \mu \mathrm{M}$ LY294002 (in 0.1\% DMSO) for $60 \mathrm{~min}$, then exposed to $10 \mathrm{nM}$ IGF-I and $20 \mu \mathrm{M}$ LY294002 for $60 \mathrm{~min}$, do not exhibit concentrated phospho-Akt in the nucleus and look similar to control treated DRG neurons.

We also analyzed phospho-Akt localization in glucose treated DRG to establish whether IGF-I elicits the same translocation pattern under these conditions (Fig. 5B). After treatment with glucose for 15 min, DRG exhibit phospho-Akt in the cell bodies similar to that of control cells (Fig. 5B). However, addition of IGF-I for 15 min with glucose induces accumulation of phosphoAkt in the nuclei of DRG neurons (arrow), similar to that of IGF-I treated neurons in control media.

\section{IGF-I causes nuclear FKHR phosphorylation}

We demonstrated that IGF-I phosphorylates FKHR on Ser256 in DRG neurons (Fig. 4A). Phosphorylation at the Ser256 site is critical for suppression of FKHR transactivating function and translocation out of the nucleus (27). Therefore, to determine IGF-I regulation of FKHR localization, we examined IGF-I treated DRG neurons for phospho-FKHR localization via immunocytochemistry (ig. 6). DRG neurons exhibited low-level cytoplasmic phospho-FKHR staining in control conditions (data not shown). To isolate IGF-I's effect on localization, this basal level of phospho-FKHR was set as a "zero" value [demonstrated in the control (C) panel of Fig. 6A]. As such, this analysis is optimized to detect the increase in phospho-FKHR resulting 
from IGF-I treatment. Addition of IGF-I for 5 min produces a robust increase in phospho-FKHR in the cell body (red) and the nucleus (pink, due to overlap of red pFKHR and blue-stained nuclei; arrows, Fig. 6A). By 15 min of IGF-I treatment, less phospho-FKHR was found in the nuclei of DRG neurons, but most neurons exhibited phospho-FKHR in the extra-nuclear cell body region (arrows). After 30 min of IGF-I treatment, most neurons exhibit only phosphoFKHR in extra-nuclear regions (arrowheads). The change in localization is not due to decreased phosphorylation of p-FKHR between 15 and 30 min (demonstrated in Fig. 4A and $\underline{B}$ ). We also examined phospho-FKHR localization in neurons treated with high glucose and IGF-I for $5 \mathrm{~min}$ (Fig. 6B). IGF-I produces the same trend in phospho-FKHR localization in high-glucose media as that seen in control media (arrows). Addition of glucose + IGF-I + LY294002 for 5 min reduces phospho-FKHR levels in most neurons to control levels (arrowheads).

\section{High glucose up-regulates Bim but not Bcl-xL in DRG neurons}

One transcriptional target of the FOXO transcription factor is the protein Bim (28). Bim is a proapoptotic member of the Bcl protein family, along with Bax and Bak. Bim can enact neuronal apoptosis presumably by binding Bax and inducing mitochondrial dysfunction (29) or by binding and inactivating anti-apoptotic Bcl proteins such as Bcl-2 and Bcl-xL (30). Interestingly, the FOXO family of FKHR transcription factors regulates Bim transcription in cerebellar granule neurons (11) and peripheral sympathetic neurons (28). IGF-I regulates FKHR phosphorylation in DRG neurons; therefore, we were interested in the effects of high glucose and IGF-I on Bim expression. DRG neurons were treated with control media or high glucose $\pm 10 \mathrm{nM}$ IGF-I for $3 \mathrm{~h}$ and analyzed via immunoblotting (Fig. 7A). We analyzed for the shortest of the three Bim isoforms, Bim ; this is considered the most pro-apoptotic form because it is not retained by the dynein motor complex and is therefore free to translocate to the mitochondria and inflict injury (11). Bim $\mathrm{s}_{\mathrm{s}}$ expression is low in control media, but high glucose treatment increases $\mathrm{Bim}_{\mathrm{s}}$ protein expression in DRG neurons (Fig. 7A). Interestingly, IGF-I does not prevent this glucose-induced increase in $\mathrm{Bim}_{\mathrm{s}}$ expression. However, the IGF-I signaling system is clearly operative, demonstrated by the increased Akt phosphorylation (pAkt) induced by IGF-I. Blocking the PI3K/Akt pathway by addition of LY294002 with high glucose does not alter Bim protein levels compared with high glucose alone. Densitometric analyses (Fig. 7B) suggest that the increase in $\mathrm{Bim}_{\mathrm{s}}$ expression with high glucose is significant $(P<0.05)$. However, we found no significant changes in samples treated with glucose and IGF-I with DMSO or LY294002 compared with glucose alone $(P>0.05)$.

We also analyzed DRG neurons for expression of the anti-apoptotic Bcl protein, Bcl-xL. DRG neurons were treated with control or high-glucose media $\pm 10 \mathrm{nM}$ IGF-I and either 0.1\% DMSO or $20 \mu \mathrm{M}$ LY294002 for $3 \mathrm{~h}$ (Fig. 7A). Bcl-xL expression does not change with addition of glucose or IGF-I. Again, the lack of IGF-I regulation is not attributable to inhibited signaling, as IGF-I causes Akt phosphorylation (pAkt) and LY294002 inhibits this activation. Densitometry confirms no significant change in Bcl-xL fold expression with glucose, IGF-I, or LY294002 treatment compared with control treatment (Fig. 7B, $P>0.05$ ). 


\section{IGF-I inhibits loss of pro-caspase-9 and cleavage of caspase-3 in glucose-treated DRG neurons via the PI3K pathway}

In addition to the $\mathrm{Bcl}$ proteins, the cysteine protease family of caspases also affects apoptosis. Caspases are zymogens that are present in inactive pro-forms in healthy cells but are cleaved in response to apoptotic stimuli (31). Activation of "initiator caspases" (caspase-8 and -9) leads to activation of executioner caspases (such as caspase-3, -6, and -7) that commit cells to apoptotic death. Caspase-8 mediates "extrinsic apoptosis", initiated by external death receptors. Caspase-9 mediates "intrinsic apoptosis" after activation by Apaf-1 and cytochrome $c$ release from mitochondria in response to adverse stimuli (32). To establish whether a particular initiator caspase (-8 or -9 ) was involved in glucose-mediated apoptosis, we treated DRG neurons for 1-3 $\mathrm{h}$ with control media or high glucose $\pm 10 \mathrm{nM}$ IGF-I and analyzed caspase expression via immunoblotting (Fig. 8A) and subsequent densitometry (Fig. 8B). Treatment with high glucose for $1-3 \mathrm{~h}$ does not increase caspase-8 cleavage in DRG neurons $(P>0.05)$. However, $3 \mathrm{~h}$ highglucose treatment causes a decrease in caspase-9 pro-form compared with control. IGF-I restores pro-casapse-9 levels back to control levels. The fold-changes in pro-caspase- 9 expression are significant between the control, glucose, and IGF-I treated samples (Fig. 8B, $P<0.05$ ). Additionally, $3 \mathrm{~h}$ high-glucose treatment increases caspase-3 cleavage in DRG neurons (Fig. 8A and $\underline{B}, P<0.05$ ). IGF-I potently inhibits glucose-induced caspase- 3 cleavage, even reducing it to levels lower than that of control cells (Fig. $8 A$ and $\underline{B} ; P<0.01)$.

We next examined caspase-3 cleavage in DRG neurons treated with glucose and either the MEK pathway inhibitor PD98059 or the PI3K pathway inhibitor LY294002 (Fig. 8C and D). Each inhibitor specifically inhibits its target pathway, shown by the ERK/Phospho-ERK and Akt/Phospho-Akt immunoblots. Caspase-3 cleavage is initiated in high-glucose media, with no additional cleavage with DMSO. In contrast, caspase-3 cleavage is suppressed with addition of IGF-I. PD98059 has no effect on IGF-I blockage of caspase-3 cleavage. However, LY294002 prevents IGF-I protection, with caspase-3 cleavage similar to that of glucose-treated DRG neurons. Densitometric analyses (Fig. $8 D$ ) demonstrate that, compared with controls, increased fold changes in phospho-Akt correlate with decreased fold changes in cleaved caspase-3, and these changes are statistically significant $(P<0.05)$.

\section{DISCUSSION}

We are interested in understanding the neuroprotective effects of IGF-I with the goal of using IGF-I as a therapy in nervous system diseases. In this study, we examined IGF-I downstream signaling in primary sensory neurons. Our results indicate that IGF-I activates the PI3K/Akt pathway in DRG neurons within 15 min and lasts at least $3 \mathrm{~h}$. These data are in contrast to IGF-I activation of Akt in transformed neural cell lines, where activation is transient and peaks within 15 min (7). However, previous reports show IGF-I activation of Akt in primary adult sensory neurons at 6,12 , and $24 \mathrm{~h}(5)$. These data suggest that IGF-I signaling mediates short- and longterm Akt activation in primary neurons. Further, our data show that IGF-I activation of Akt occurs in high glucose; thus, an apoptotic environment does not interrupt IGF-I mediated survival signaling.

In our current study, IGF-I inhibits glucose-induced apoptosis in DRG neurons via the PI3K/Akt pathway. In agreement with these results, IGF-I blocks apoptosis in DRG neurons after NGF 
withdrawal via the PI3K/Akt pathway and not the ERK/MAPK pathway (4). Our data also indicate that ERK/MAPK pathway activation is not altered by IGF-I and that sustained presence of NGF is not sufficient to protect DRG neurons from glucose-mediated apoptosis. NGF is present at receptor-saturating concentrations in culture media, which may account for the steadystate signaling through ERK/MAPK. IGF-I may be protective in DRG neurons because it can signal through a survival pathway, PI3K/Akt, which is not already "on” at high levels. Interestingly, embryonic DRG neurons lose their dependence on NGF both in vivo and after 21 days in culture, inferring that NGF-activated signaling pathways are not critical for ultimate survival (33). A similar situation occurs during IGF-I mediated neurite outgrowth. For example, blocking the MAPK pathway does not impair IGF-I stimulated neurite outgrowth in adult DRG neurons, but the PI3K pathway is important for IGF-I stimulated neurite outgrowth (5). Thus, IGF-I activation of PI3K/Akt is instrumental in DRG neuronal neurite outgrowth and neuroprotection. These data collectively suggest that IGF-I could promote a potent survival and regenerative effect (via activation of the PI3K/Akt pathway) in adult in vivo neurons, which are no longer exposed to, or dependent on, NGF signaling.

Our data implicate cytoplasmic and nuclear Akt effectors in IGF-I mediated neuroprotection. We demonstrate IGF-I phosphorylation of GSK-3 $\beta$ within $15 \mathrm{~min}$ in control and high-glucose conditions. GSK-3 $\beta$ promotes apoptosis in central nervous system (CNS) and peripheral nervous system (PNS) neurons when it is active (i.e., not phosphorylated; 34). We also show IGF-Iinduced CREB phosphorylation in control and high-glucose conditions that is inhibited by LY294002. IGF-I increases CREB-mediated transcription in control and apoptotic conditions, suggesting that IGF-I up-regulates survival proteins in DRG neurons. Several lines of evidence corroborate the importance of CREB in neuroprotection. CREB phosphorylation inhibits apoptosis in other neurons (35), and loss of CREB results in impaired axonal growth and excessive apoptosis of peripheral sensory and sympathetic neurons (36). Although the targets of IGF-I induced CREB transcription are not currently known in DRG neurons, several CREcontaining survival genes are known, such as brain-derived neurotrophic factor and IGF-I itself (26, 37). Thus, CREB activation may amplify the IGF-I neuroprotective response by increasing growth factor expression to mediate long-term survival.

In the current study, we demonstrate that IGF-I causes active Akt to accumulate in the nuclei of DRG neurons. This localization suggests that Akt can directly activate nuclear transcription factors. Inhibition of the PI3K/Akt pathway blocks increased nuclear accumulation of Akt, allowing glucose-mediated apoptosis to occur. Thus, nuclear re-distribution of active Akt may be one means of IGF-I mediated protection, followed by nuclear activation of CREB. Additionally, redistribution to the nucleus correlates with the timeline of IGF-I mediated FKHR phosphorylation and the decrease of phospo-FKHR in the nuclei of DRG neurons. Akt-mediated phosphorylation decreases the DNA binding ability of FKHR, causing it to be exported from the nucleus (27). Preventing nuclear localization of FKHR inhibits transcription required for apoptosis (25). Our data similarly suggest that IGF-I protects DRG neurons by excluding FKHR from the nucleus. Thus, IGF-I regulates nuclear transcription via blocking pro-apoptotic transcription factors (FKHR) and by activating survival transcription factors (CREB).

Although the full array of FKHR transcriptional targets is unknown, one reported target is Bim, a pro-apoptotic member of the Bcl family (28). FKHR increases Bim transcription in cerebellar granule neurons and sympathetic neurons and is important in neuronal apoptosis (29). We 
demonstrate that high glucose increases Bim protein levels in DRG neurons, but contrary to reports in cerebellar granule neurons, IGF-I does not inhibit this increase (11). Inhibition of PI3K/Akt does not decrease Bim protein to control levels, consistent with findings in sympathetic neurons (29). Thus, peripheral sympathetic and sensory neurons do not conform to the same profile of PI3K/Akt and FKHR regulation of Bim transcription seen in CNS neurons. Although IGF-I does not regulate expression of $\mathrm{Bcl}$ proteins, it may regulate their localization. Maintaining pro-apoptotic Bcl proteins (e.g., Bim, Bax) in the cytosol and away from the mitochondrial membrane could protect neurons from mitochondrial damage and apoptosis. IGF-I may act similar to NGF, which prevents Bax localization at mitochondria in cisplatin-treated DRG neurons (38). Additionally, IGF-I may stabilize anti-apoptotic Bcl-2/Bcl-xL dimers, thereby preventing their heterodimerization with pro-apoptotic Bim, and injurious translocation to the mitochondria.

We have previously reported that high glucose induces apoptosis of DRG neurons via production of increased reactive oxygen species and oxidative stress, resulting in mitochondrial dysfunction and cytochrome $c$ release into the cytoplasm (12). In the current study, high glucose also activates the caspase cascade via loss of the caspase- 9 proform and increased cleavage of downstream caspase-3. We examined caspases $-8,-9$, and -3 at early time points to detect initiator caspase action. Loss of caspase- 9 proform occurred at $3 \mathrm{~h}$, although caspase-3 cleavage is present as early as $1 \mathrm{~h}$ post-glucose treatment. It is likely that high glucose activates the caspase- 9 cascade at earlier time points $(<1 \mathrm{~h})$ but is undetectable due to unamplified caspaseactivation. Caspases -9 and -3 operate in a feedback amplification loop, such that initial low levels of activated caspase- 9 lead to caspase- 3 activation, but full caspase- 9 processing is achieved only after caspase-3 activation (39). At $3 \mathrm{~h}$, following an amplification effect, we detect both loss of caspase- 9 and increased caspase- 3 cleavage. We have reported glucose-mediated mitochondrial increases in reactive oxygen species in DRG neurons within $1 \mathrm{~h}$, with mitochondrial damage and cytochrome $c$ release at 3 and $6 \mathrm{~h}$, respectively (12). Caspase-9 is activated by cytochrome $c$, so together these results suggest that high glucose induces mitochondrial dysfunction, release of cytochrome $c$ into the cytoplasm, and activation of the caspase- 9 cascade after $3 \mathrm{~h}$. Our results additionally demonstrate that IGF-I inhibits loss of proform caspase- 9 and caspase-3 cleavage in high glucose through the PI3K/Akt pathway. Akt phosphorylates a serine residue of caspase-9, inhibiting its protease activity and apoptosis (40); therefore, Akt may regulate caspase-9 activity via phosphorylation. Collectively, our results suggest that IGF-I inhibits high-glucose-induced caspase activation through the PI3K/Akt pathway, contributing to IGF-I mediated neuroprotection in DRG neurons.

In conclusion, our data establish that IGF-I is neuroprotective for glucose-treated DRG neurons through the PI3K/Akt pathway, via regulation of cytoplasmic and nuclear factors and suppression of caspase activation. IGF-I does not regulate $\mathrm{Bcl}$ protein expression but may alter $\mathrm{Bcl}$ protein localization. Together, our data support a pluripotent role for IGF-I in neuronal survival at both the cytoplasmic and nuclear levels.

\section{ACKNOWLEDGMENTS}

The authors wish to thank Duane Leinninger II for help with figure preparation. This work was supported by the National Institutes of Health (NS36778, NS38849 and NS43023), the Juvenile Diabetes Research Foundation, and the Program for Understanding Neurological Diseases 
(PFUND). This work was also supported by awards HG02367 and DK063340 from the National Institutes of Health to M.D.U. Potential conflicts of interest between these NIH-sponsored research activities and activities related to Originus, Inc., are managed by the University of Michigan Medical School Conflict of Interest Committee.

\section{REFERENCES}

1. Gao, W. Q., Shinsky, N., Ingle, G., Beck, K., Elias, K. A., and Powell-Braxton, L. (1999) IGF-I deficient mice show reduced peripheral nerve conduction velocities and decreased axonal diameters and respond to exogenous IGF- I treatment. J. Neurobiol. 39, 142-152

2. Leinninger, G. M., Meyer, G. E., and Feldman, E. L. (2003) IGFs and the Nervous System. In Insulin-Like Growth Factors (LeRoith, D., Zumkeller, W., and Baxter, R., eds) Eurekah.com, http://www.eurekah.com/chapter.php?chapid=975\&bookid=34\&catid=19

3. Lewis, M. E., Neff, N. T., Contreras, P. C., Stong, D. B., Oppenheim, R. W., Grebow, P. E., and Vaught, J. L. (1993) Insulin-like growth factor-I: Potential for treatment of motor neuronal disorders. Exp. Neurol. 124, 73-88

4. Russell, J. W., Windebank, A. J., Schenone, A., and Feldman, E. L. (1998) Insulin-like growth factor-I prevents apoptosis in neurons after nerve growth factor withdrawal. $J$. Neurobiol. 36, 455-467

5. Jones, D. M., Tucker, B. A., Rahimtula, M., and Mearow, K. M. (2003) The synergistic effects of NGF and IGF-1 on neurite growth in adult sensory neurons: convergence on the PI 3-kinase signaling pathway. J. Neurochem. 86, 1116-1128

6. Rabinovsky, E. D., Gelir, E., Gelir, S., Lui, H., Kattash, M., DeMayo, F. J., Shenaq, S. M., and Schwartz, R. J. (2003) Targeted expression of IGF-1 transgene to skeletal muscle accelerates muscle and motor neuron regeneration. FASEB J. 17, 53-55

7. van Golen, C. M., Schwab, T. S., Woods Ignatoski, K. M., Ethier, S. P., and Feldman, E. L. (2001) PTEN/MMAC1 overexpression decreases insulin-like growth factor-I-mediated protection from apoptosis in neuroblastoma cells. Cell Growth Differ. 12, 371-378

8. Párrizas, M., Saltiel, A. R., and LeRoith, D. (1997) Insulin-like growth factor 1 inhibits apoptosis using the phosphatidylinositol 3'-kinase and mitogen-activated protein kinase pathways. J. Biol. Chem. 272, 154-161

9. Zheng, W. H., Kar, S., and Quirion, R. (2002) Insulin-like growth factor-1-induced phosphorylation of transcription factor FKHRL1 is mediated by phosphatidylinositol 3kinase/Akt kinase and role of this pathway in insulin-like growth factor-1-induced survival of cultured hippocampal neurons. Mol. Pharmacol. 62, 225-233

10. Dudek, H., Datta, S. R., Franke, T. F., Birnbaum, M. J., Yao, R., Cooper, G. M., Segal, R. A., Kaplan, D. R., and Greenberg, M. E. (1997) Regulation of neuronal survival by the serine-threonine protein kinase Akt. Science 275, 661-665 
11. Linseman, D. A., Phelps, R. A., Bouchard, R. J., Le, S. S., Laessig, T. A., McClure, M. L., and Heidenreich, K. A. (2002) Insulin-like growth factor-I blocks Bcl-2 interacting mediator of cell death (Bim) induction and intrinsic death signaling in cerebellar granule neurons. $J$. Neurosci. 22, 9287-9297

12. Russell, J. W., Golovoy, D., Vincent, A. M., Mahendru, P., Olzmann, J. A., Mentzer, A., and Feldman, E. L. (2002) High glucose induced oxidative stress and mitochondrial dysfunction in neurons. FASEB J. 16, 1738-1748

13. Russell, J. W., Sullivan, K. A., Windebank, A. J., Herrmann, D. N., and Feldman, E. L. (1999) Neurons undergo apoptosis in animal and cell culture models of diabetes. Neurobiol. Dis. 6, 347-363

14. Korinkova, P., and Lodin, Z. (1976) The metabolism of glucose of nerve cells cultivated under different conditions. Acta Histochem. 56, 47-65

15. Federici, M., Hribal, M., Perego, L., Ranalli, M., Caradonna, Z., Perego, C., Usellini, L., Nano, R., Bonini, P., Bertuzzi, F., et al. (2001) High glucose causes apoptosis in cultured human pancreatic islets of Langerhans: a potential role for regulation of specific Bcl family genes toward an apoptotic cell death program. Diabetes 50, 1290-1301

16. Mayfield, J. (1998) Diagnosis and classification of diabetes mellitus: new criteria. Am. Fam. Physician 58, 1355-1370

17. Medina-Kauwe, L. K., Maguire, M., Kasahara, N., and Kedes, L. (2001) Nonviral gene delivery to human breast cancer cells by targeted Ad5 penton proteins. Gene Ther. 8, 17531761

18. Mu, X., Silos-Santiago, I., Carroll, S. L., and Snider, W. D. (1993) Neurotrophin receptor genes are expressed in distinct patterns in developing dorsal root ganglia. J. Neurosci. 13, 4029-4041

19. Federici, M., Lauro, D., D'Adamo, M., Giovannone, B., Porzio, O., Mellozzi, M., Tamburrano, G., Sbraccia, P., and Sesti, G. (1998) Expression of insulin/IGF-I hybrid receptors is increased in skeletal muscle of patients with chronic primary hyperinsulinemia. Diabetes 47, 87-92

20. Kim, B., Leventhal, P. S., Saltiel, A. R., and Feldman, E. L. (1997) Insulin-like growth factor-I-mediated neurite outgrowth in vitro requires MAP kinase activation. J. Biol. Chem. 272, 21268-21273

21. Creedon, D. J., Johnson, E. M., and Lawrence, J. C. (1996) Mitogen-activated protein kinase-independent pathways mediate the effects of nerve growth factor and cAMP on neuronal survival. J. Biol. Chem. 271, 20713-20718

22. Crowder, R. J., and Freeman, R. S. (1998) Phosphatidylinositol 3-kinase and Akt protein kinase are necessary and sufficient for the survival of nerve growth factor-dependent sympathetic neurons. J. Neurosci. 18, 2933-2943 
23. Van Obberghen, E. (1994) Signalling through the insulin receptor and the insulin-like growth factor-I receptor. Diabetologia 37, Suppl 2, S125-S134

24. Toker, A. (2000) Protein kinases as mediators of phosphoinositide 3-kinase signaling. Mol. Pharmacol. 57, 652-658

25. Tang, E. D., Nunez, G., Barr, F. G., and Guan, K. L. (1999) Negative regulation of the forkhead transcription factor FKHR by Akt. J. Biol. Chem. 274, 16741-16746

26. Mayr, B., and Montminy, M. (2001) Transcriptional regulation by the phosphorylationdependent factor CREB. Nat. Rev. Mol. Cell Biol. 2, 599-609

27. Guo, S., Rena, G., Cichy, S., He, X., Cohen, P., and Unterman, T. (1999) Phosphorylation of serine 256 by protein kinase B disrupts transactivation by FKHR and mediates effects of insulin on insulin-like growth factor-binding protein-1 promoter activity through a conserved insulin response sequence. J. Biol. Chem. 274, 17184-17192

28. Gilley, J., Coffer, P. J., and Ham, J. (2003) FOXO transcription factors directly activate bim gene expression and promote apoptosis in sympathetic neurons. J. Cell Biol. 162, 613-622

29. Putcha, G. V., Moulder, K. L., Golden, J. P., Bouillet, P., Adams, J. A., Strasser, A., and Johnson, E. M. (2001) Induction of BIM, a proapoptotic BH3-only BCL-2 family member, is critical for neuronal apoptosis. Neuron $\mathbf{2 9 ,}$, 615-628

30. Cheng, E. H., Wei, M. C., Weiler, S., Flavell, R. A., Mak, T. W., Lindsten, T., and Korsmeyer, S. J. (2001) BCL-2, BCL-X(L) sequester BH3 domain-only molecules preventing BAX- and BAK-mediated mitochondrial apoptosis. Mol. Cell 8, 705-711

31. Cohen, G. M. (1997) Caspases: the executioners of apoptosis. Biochem. J. 326, 1-16

32. Chen, M., and Wang, J. (2002) Initiator caspases in apoptosis signaling pathways. Apoptosis 7, 313-319

33. Eichler, M. E., and Rich, K. M. (1989) Death of sensory ganglion neurons after acute withdrawal of nerve growth factor in dissociated cell cultures. Brain Res. 482, 340-346

34. Hetman, M., Cavanaugh, J. E., Kimelman, D., and Xia, Z. (2000) Role of glycogen synthase kinase-3beta in neuronal apoptosis induced by trophic withdrawal. J. Neurosci. 20, 25672574

35. Walton, M., Woodgate, A. M., Muravlev, A., Xu, R., During, M. J., and Dragunow, M. (1999) CREB phosphorylation promotes nerve cell survival. J. Neurochem. 73, 1836-1842

36. Lonze, B. E., Riccio, A., Cohen, S., and Ginty, D. D. (2002) Apoptosis, axonal growth defects, and degeneration of peripheral neurons in mice lacking CREB. Neuron 34, 371-385

37. Thomas, M. J., Umayahara, Y., Shu, H., Centrella, M., Rotwein, P., and McCarthy, T. L. (1996) Identification of the cAMP response element that controls transcriptional activation 
of the insulin-like growth factor-I gene by prostaglandin E2 in osteoblasts. J. Biol. Chem. 271, 21835-21841

38. McDonald, E. S., and Windebank, A. J. (2002) Cisplatin-induced apoptosis of DRG neurons involves bax redistribution and cytochrome c release but not fas receptor signaling. Neurobiol. Dis. 9, 220-233

39. Fujita, E., Egashira, J., Urase, K., Kuida, K., and Momoi, T. (2001) Caspase-9 processing by caspase-3 via a feedback amplification loop in vivo. Cell Death Differ. 8, 335-344

40. Cardone, M. H., Roy, N., Stennicke, H. R., Salvesen, G. S., Franke, T. F., Stanbridge, E., Frisch, S., and Reed, J. C. (1998) Regulation of cell death protease caspase-9 by phosphorylation. Science 282, 1318-1321

Received Feb 10, 2004; accepted, June 28, 2004 
Fig. 1
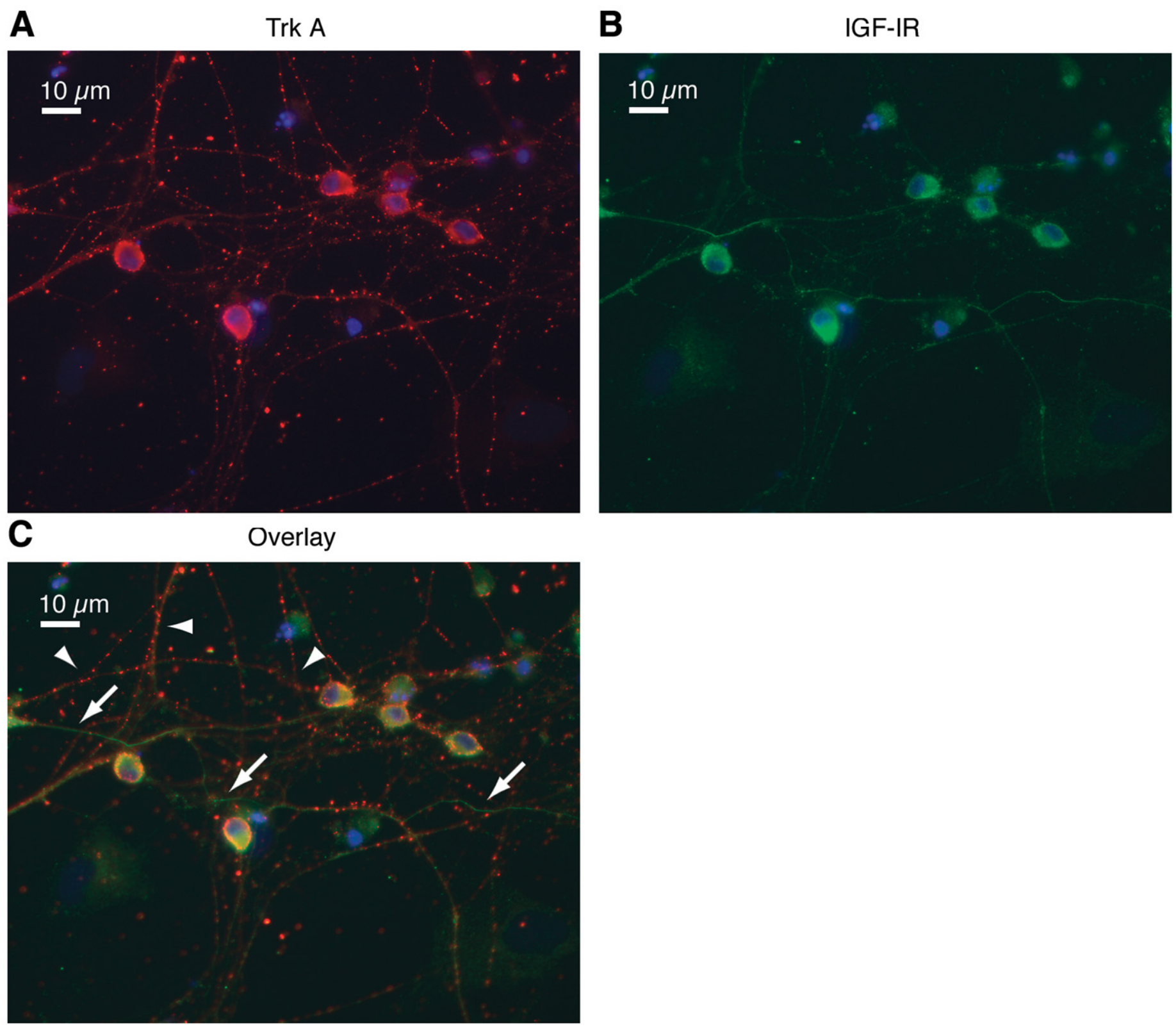

Figure 1. DRG neurons express TrkA and IGF-I receptors. DRG neurons were fixed and assayed by immunocytochemistry for TrkA (red), IGF-IR (green), and nuclei (blue, via Hoechst 33342 staining). $\boldsymbol{A}$ ) TrkA (red) is expressed evenly in extra-nuclear regions of cell bodies and in a punctate pattern in neurites. $\boldsymbol{B}$ ) IGF-IR is expressed in the extra-nuclear regions of cell bodies and in neurites. $\boldsymbol{C}$ ) Images of TrkA (red), IGF-IR (green), and nuclei (blue) are overlaid, demonstrating co-expression of TrkA and IGF-IR in the extra-nuclear cell body regions of DRG neurons (yellow). Though TrkA and IGF-IR are co-expressed in some DRG neurites, many neurites predominantly express either TrkA (arrowheads) or IGF-IR (arrows). Scale bars $=10 \mu \mathrm{m}$. 
Fig. 2
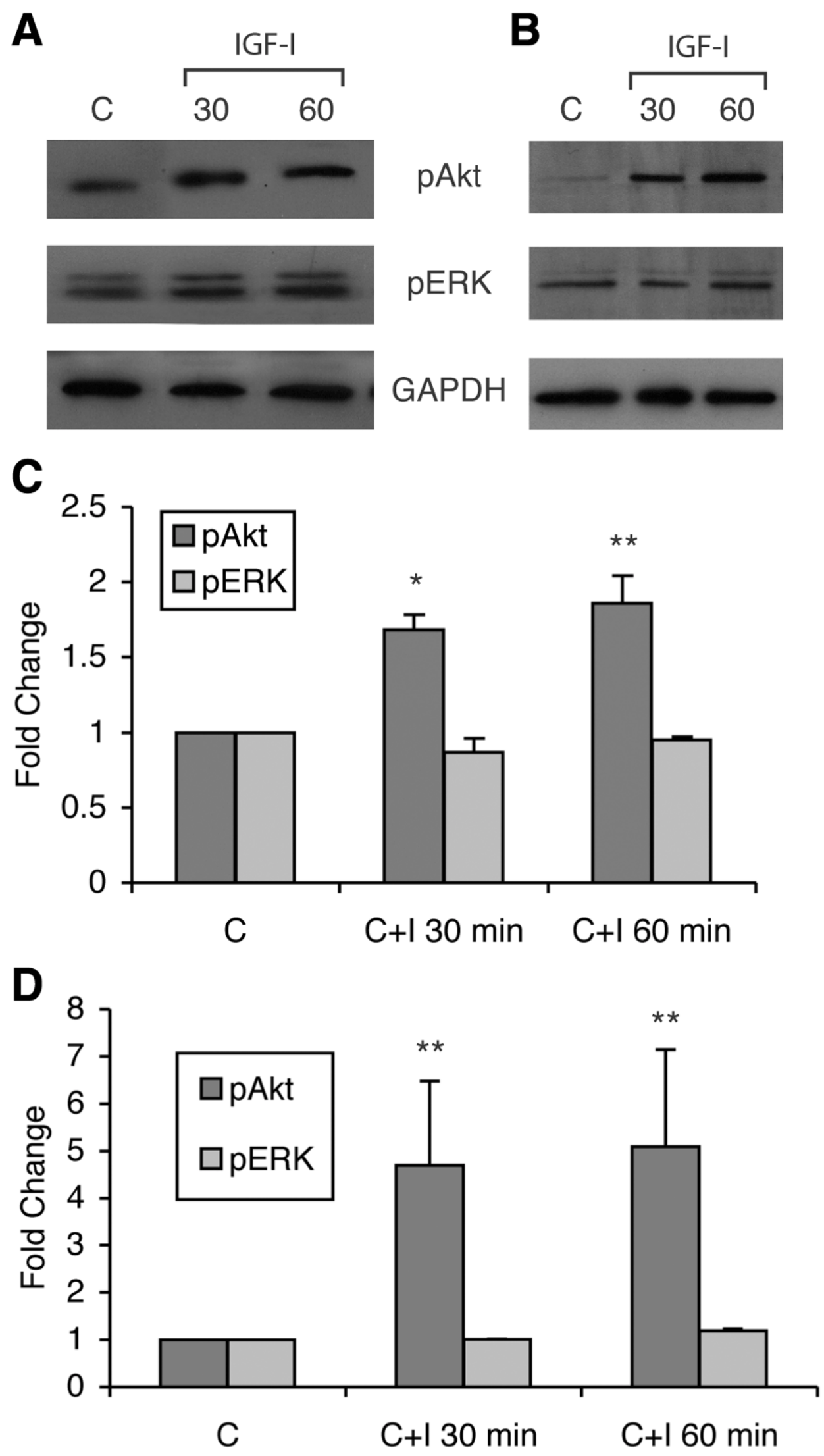
Figure 2. IGF-I activates Akt, but not ERK in DRG neurons. $\boldsymbol{A}$ ) DRG neurons were treated with $10 \mathrm{nM}$ IGF-I for 0, 30, or $60 \mathrm{~min}$ and assayed via immunoblotting. Akt phosphorylation (pAkt) increases at $30 \mathrm{~min}$ of IGF-I treatment and remains increased throughout the time course. ERK phosphorylation (pERK) does not change with IGF-I addition.

Immunoblots for GAPDH indicate equal protein levels between samples, suggesting that phosphorylation differences are not due to unequal protein loading. Immunoblots shown are representative of results from three separate experiments. $\boldsymbol{B})$ DRG neurons were deprived of NGF for $3 \mathrm{~h}$ and treated with antibodies against NGF. DRG neurons were then stimulated with $10 \mathrm{nM}$ IGF-I for 0, 30, and $60 \mathrm{~min}$ in the absence of NGF and in the presence of anti-NGF antibodies. Immunoblots show that Akt (labeled pAkt) is phosphorylated by IGF-I addition after $30 \mathrm{~min}$ and remains phosphorylated throughout the time course. However, ERK phosphorylation (labeled pERK) is not altered by IGF-I treatment. Immunoblots for GAPDH indicate equal protein levels between samples, suggesting that phosphorylation differences are not due to unequal protein loading. Immunoblots shown are representative of results from three separate experiments. $\boldsymbol{C}$ ) Densitometry of DRG neurons treated with $10 \mathrm{nM}$ IGF-I for 0, 30, or $60 \mathrm{~min}$ and assayed via immunoblotting (as shown in $\boldsymbol{A}$ ). Expression is represented as the average fold change of samples compared with the controls $(\mathrm{C})$, such that $\mathrm{C}=1$. Error bars represent standard error of the mean (SEM). D) Densitometry of DRG neurons deprived of NGF for $3 \mathrm{~h}$ and treated with antibodies against NGF (as shown in $\boldsymbol{B}$ ). Expression is represented as the average fold change of samples compared with the controls $(\boldsymbol{C})$, such that $\mathrm{C}=1$. Error bars represent standard error of the mean (SEM). For all graphs $* P<0.05$ and $* * P<0.01$ as determined by one-way ANOVA. 
Fig. 3

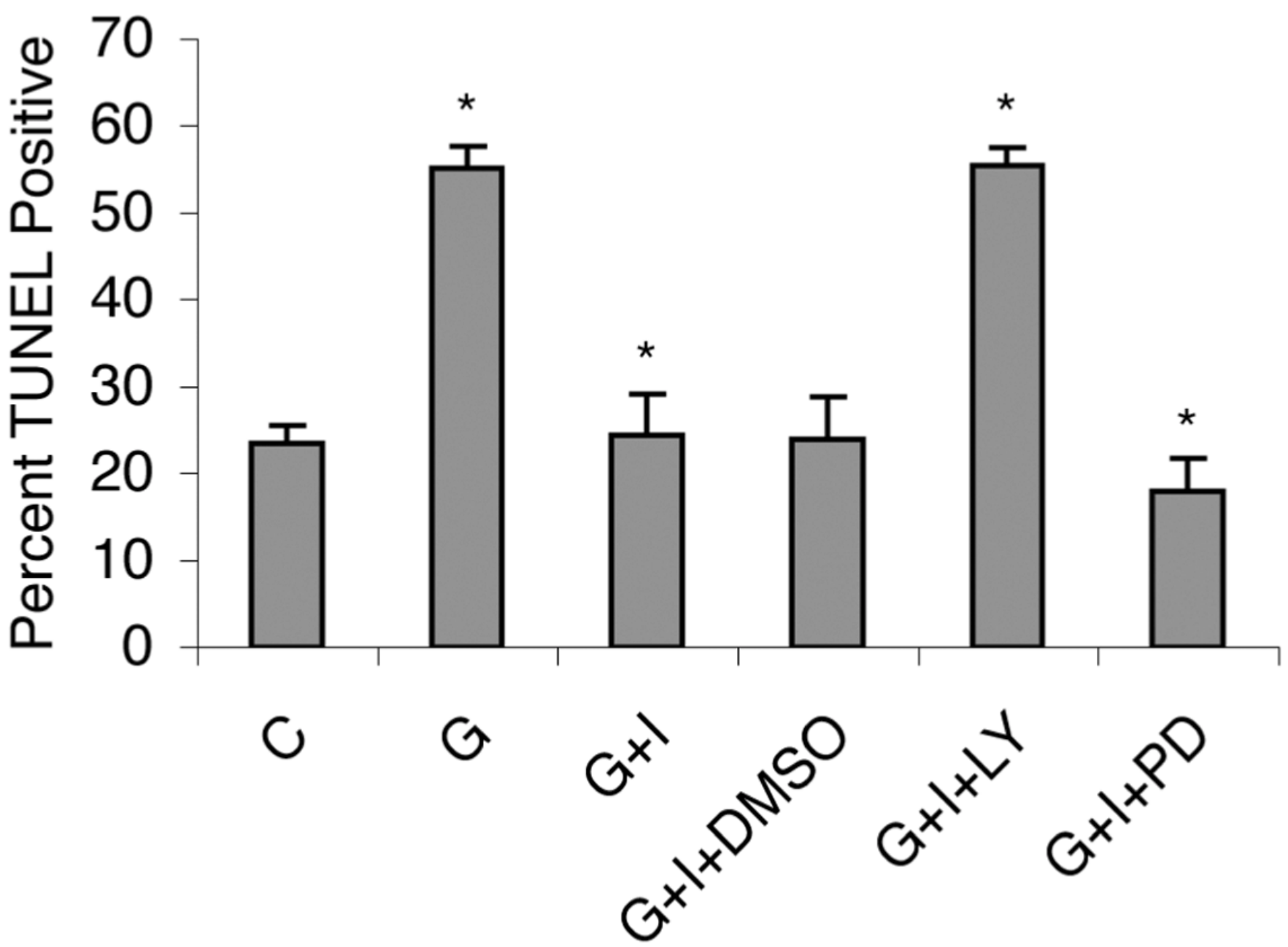

Figure 3. IGF-I inhibits high glucose-induced apoptosis via the PI3K pathway. DRG neurons were treated for $24 \mathrm{~h}$ in control (C), glucose $(\mathrm{G})$, glucose $+10 \mathrm{nM}$ IGF-I (G+I), glucose $+0.1 \%$ DMSO (G+I+DMSO) or glucose $+20 \mu \mathrm{M}$ LY294002 or PD98059 inhibitors (G+I+LY and G+I+PD). High glucose significantly increases apoptosis compared with control media (G vs. C). Addition of IGF-I significantly decreases glucose-induced apoptosis, comparable with control levels (G+I vs. G). Treatment with G+I+LY294002 yields significantly higher apoptosis than DRG neurons treated with IGF-I and DMSO (G+I+LY vs. G+I+DMSO). However, treatment with PD98059 + IGF-I rescues cells significantly compared with glucose treatment alone (compare G+I+PD to G). Addition of DMSO, the vehicle that the LY294002 and PD98049 are dissolved in, does not affect IGF-I rescue. Error bars represent the standard error of the mean (SEM). Differences are significant between samples (marked with asterisk) if $P$ value is $P<0.01$, as determined by Students' $t$ test. 
Fig. 4

A

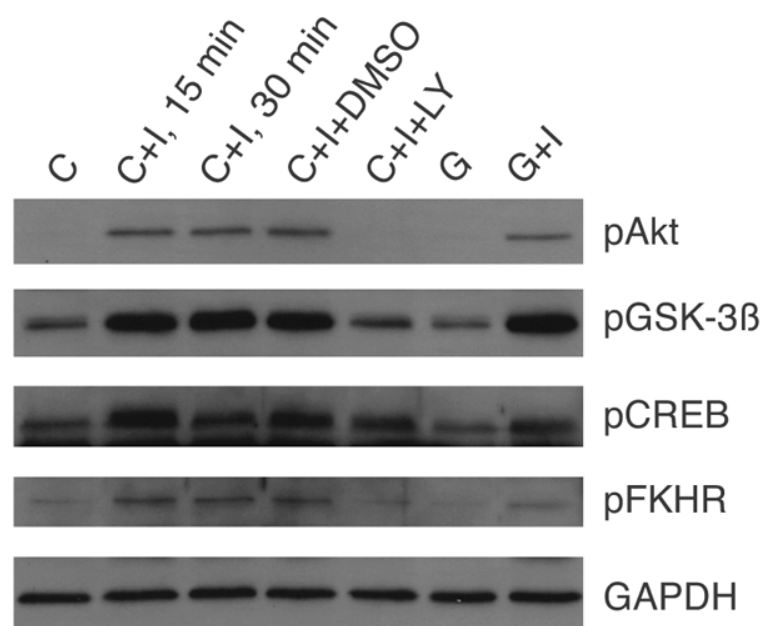

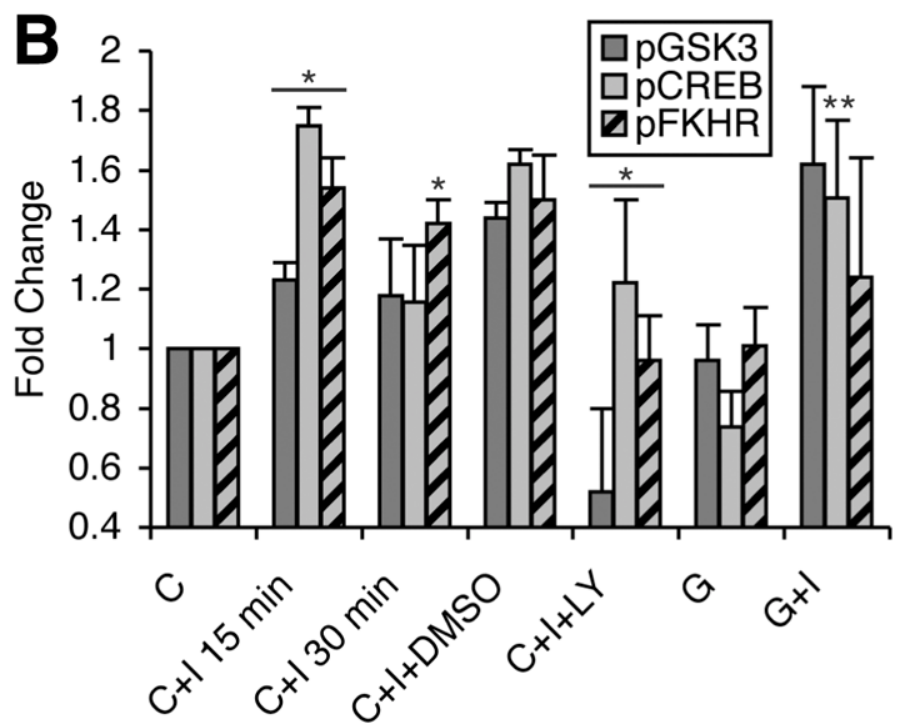

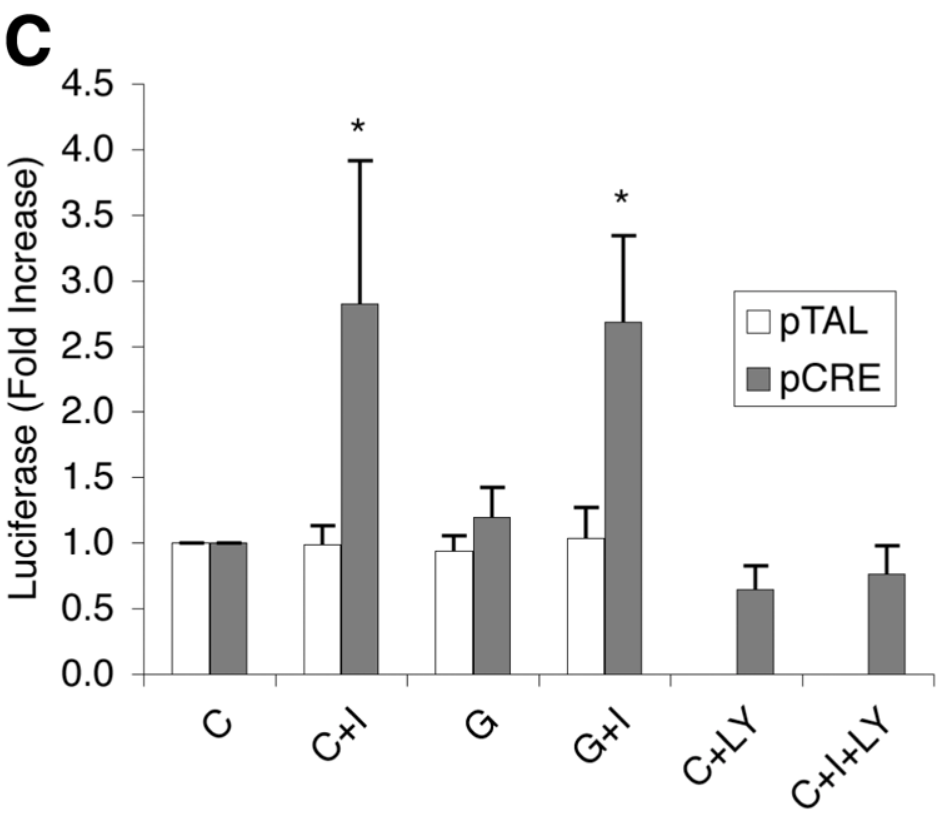

Figure 4. IGF-I regulates the Akt effectors GSK-3 $\beta$, CREB, and FKHR. $A$ ) DRG neurons were treated with control media (C) or stimulated with $10 \mathrm{nM}$ IGF-I for $15 \mathrm{~min}(\mathrm{C}+\mathrm{I}, 15 \mathrm{~min})$ or $30 \mathrm{~min}(\mathrm{C}+\mathrm{I}, 30 \mathrm{~min})$. DRG neurons were also treated for 15 min with $10 \mathrm{nM}$ IGF-I and 0.1\% DMSO (C+I+DMSO) or LY294002 (C+I+LY), or separately with glucose (G) or glucose $+10 \mathrm{nM}$ IGF-I (G+I). The phospho-Akt (p-Akt) immunoblot verifies that IGF-I activates Akt in IGF-I stimulated control and glucose media, but that LY294002 inhibits IGF-I mediated p-Akt activation to control levels. IGF-I causes GSK-3 $\beta$ phosphorylation (pGSK-3 $\beta$ ) in control and high glucose, which is inhibited by LY294002. IGF-I also induces CREB phosphorylation (pCREB) after $15 \mathrm{~min}$, but phosphorylation decreases by $30 \mathrm{~min}$. CREB phosphorylation is inhibited by LY294002, and CREB can be activated in high glucose conditions. The apoptotic FKHR transcription factor is phosphorylated by IGF-I at 15 and $30 \mathrm{~min}$ (pFKHR), and this phosphorylation is inhibited by LY294002. IGF-I also phosphorylates FKHR in high glucose media, suggesting that an apoptotic environment does not negate IGF-I protective signaling. These phosphorylation differences are not due to unequal protein loading, as demonstrated by the equivalent GAPDH bands. Immunoblots shown are representative of results from three separate experiments. $\boldsymbol{B}$ ) Densitometry of pGSK-3 $\beta$, pCREB, and pFKHR from immunoblots described in $(\boldsymbol{A})$. Expression is represented as the average fold change of samples compared to the controls $(\mathrm{C})$, such that $\mathrm{C}=1$. Error bars represent standard error of the mean (SEM). *Denotes a $P$ value that is $P<0.05$ or less as determined by one-way ANOVA. $\boldsymbol{C}$ ) DRG neurons were transfected with plasmids containing control (pTAL) or CRE (pCRE) promoters directing expression of a firefly luciferase 


\section{Fig. 4 (cont)}

reporter gene. DRG neurons were also transfected with a plasmid containing a constitutively active renilla luciferase reporter, used to normalize transfection levels between samples. Results are expressed as fold increase of luciferase fluorescence normalized to control treatment. DRG neurons were treated for $24 \mathrm{~h}$ with control media alone $(\mathrm{C})$ or with 10

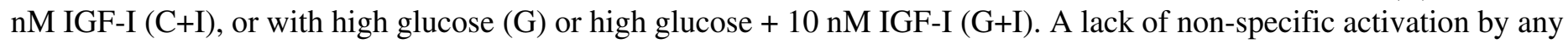
of the treatments was determined, as shown by the equivalent pTAL luciferase fold output $(n=3)$. Addition of IGF-I to control media significantly increases CRE binding over control by 2.8 -fold $(P<0.005, n=6)$. High glucose induction of CRE-dependent transcription is not statistically significant $(P>0.05)$, but addition of IGF-I to high glucose significantly increases CRE binding over control by 2.7 -fold $(P<0.005, n=6)$. DRG neurons were also treated for $24 \mathrm{~h}$ with control media $+20 \mu \mathrm{M} \mathrm{LY} 294002(\mathrm{C}+\mathrm{LY})$ and $10 \mathrm{nM}$ IGF-I (C+I+LY) to determine the contributions of the PI3K/Akt pathway to basal and IGF-I induced CRE-transcription. Blocking the PI3K/Akt pathway slightly inhibits CREB-mediated CRE transcription in $\mathrm{C}+\mathrm{LY}$ and $\mathrm{C}+\mathrm{I}+\mathrm{LY}$ samples compared with control-treated neurons. Differences are significant $(*)$ if $P<$ 0.005 as determined by Students' $t$-test, using a two-tailed test and assuming equal variances. 
Fig. 5

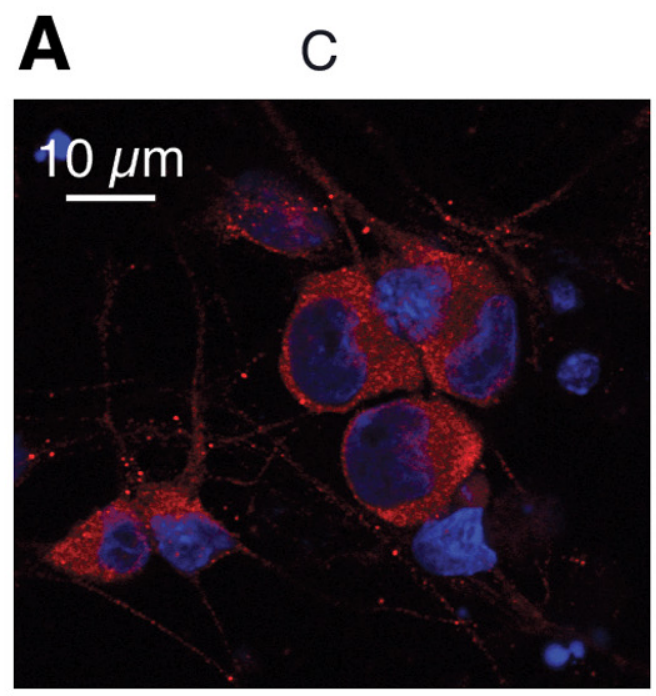

$C+\mathrm{I}, 15 \mathrm{~min}$

$$
\mathrm{C}+\mathrm{I}, 60 \mathrm{~min}
$$

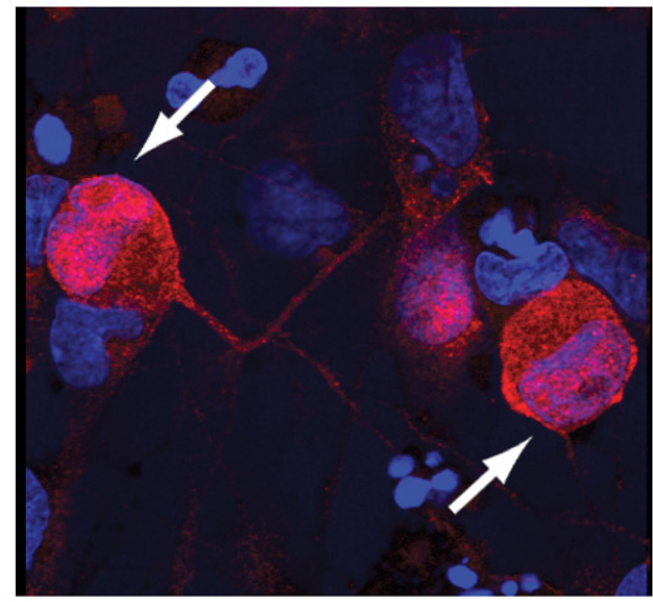

B

G, 15 min

\section{$10 \mu \mathrm{m}$}

$C+I+L Y, 60 \mathrm{~min}$

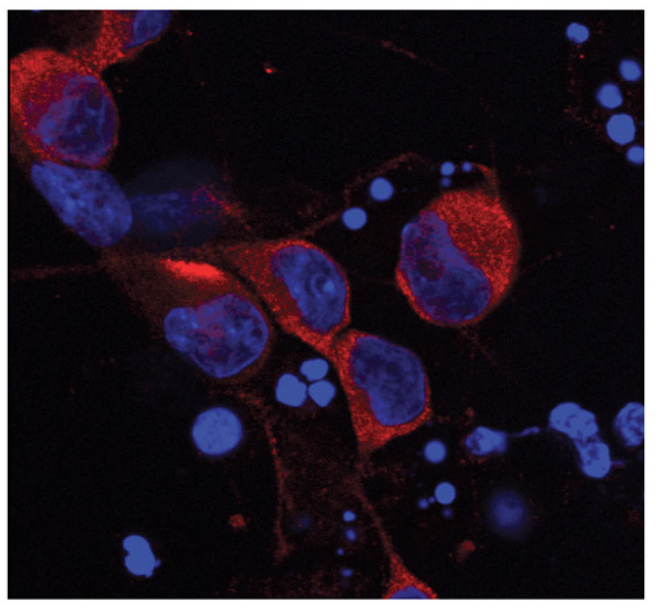

$G+I, 15$ min

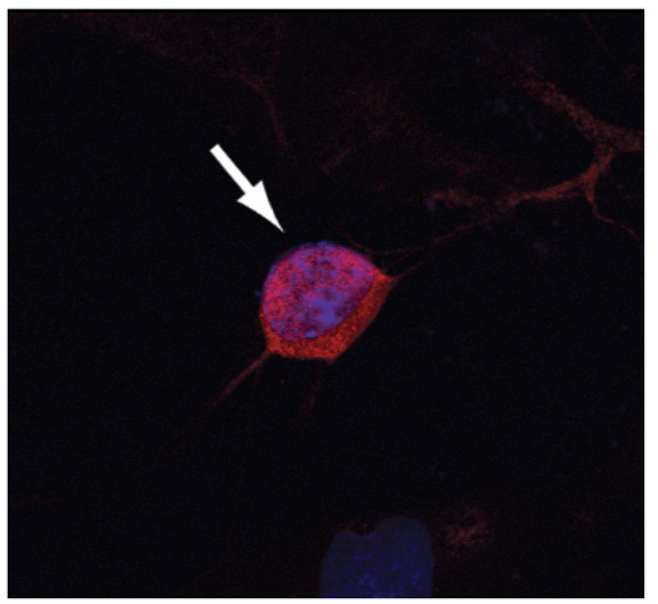


Figure 5. IGF-I induces accumulation of phospho-Akt in the nuclei of DRG neurons. $A$ ) DRG neurons were treated with NB media (C) or NB media $+10 \mathrm{nM}$ IGF-I for $15(\mathrm{C}+\mathrm{I}, 15 \mathrm{~min})$ or $60 \mathrm{~min}(\mathrm{C}+\mathrm{I}, 60 \mathrm{~min})$. All samples were probed with antibodies against phospho-Akt ser473 (red), and nuclei were labeled with Hoechst 33342 dye (blue). Control DRG neurons exhibit phospho-Akt in the extra-nuclear regions of cell bodies. Addition of IGF-I for 15 min causes some phospho-Akt accumulation in nuclei (arrow), represented by punctate pink nuclear staining (overlap of red phospho-Akt and blue nuclei). Addition of IGF-I for $60 \mathrm{~min}$ greatly increases the nuclear localization of phospho-Akt in many DRG neurons, represented by the intense pink staining in the nuclei. However, DRG neurons treated with $10 \mathrm{nM}$ IGF-I and 20 $\mu \mathrm{M}$ LY294002 resemble control-treated neurons, with phospho-Akt located outside of the nuclei. B) DRG neurons were treated with glucose alone (G, $15 \mathrm{~min})$ or with glucose $+10 \mathrm{nM}$ IGF-I for $15 \mathrm{~min}(\mathrm{G}+\mathrm{I}, 15 \mathrm{~min})$ and assayed by immunocytochemistry as described in $(\boldsymbol{A})$. Neurons treated with glucose alone exhibit only extra-nuclear localization of phospho-Akt. However, addition of IGF-I results in pronounced accumulation of phospho-Akt in the nucleus (arrow). 
Fig. 6

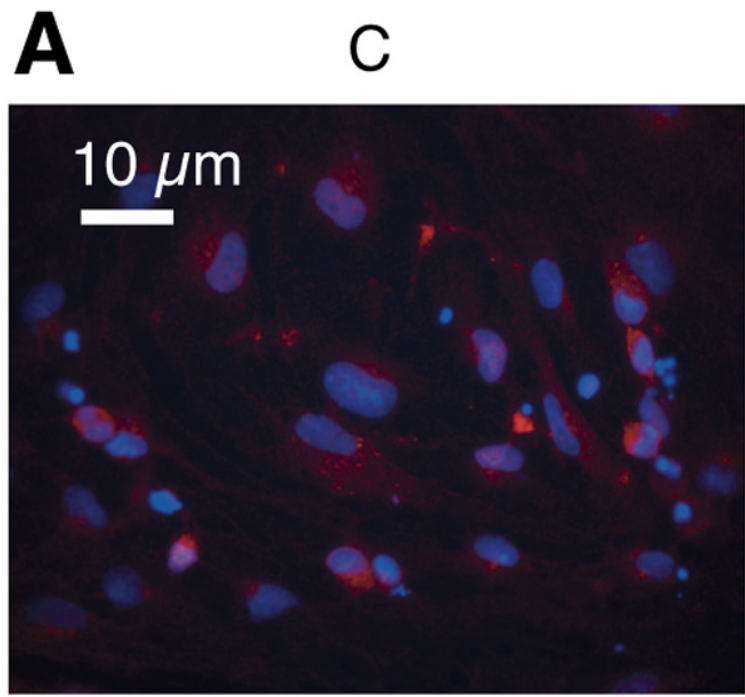

$\mathrm{C}+\mathrm{I}, 5 \mathrm{~min}$

\section{$\mathrm{C}+\mathrm{I}, 15 \mathrm{~min}$}

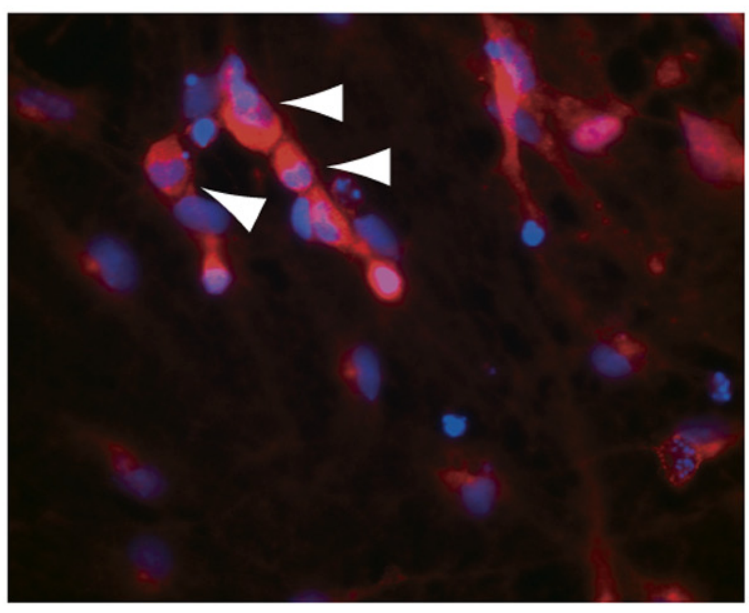

$\mathrm{C}+\mathrm{I}, 30 \mathrm{~min}$

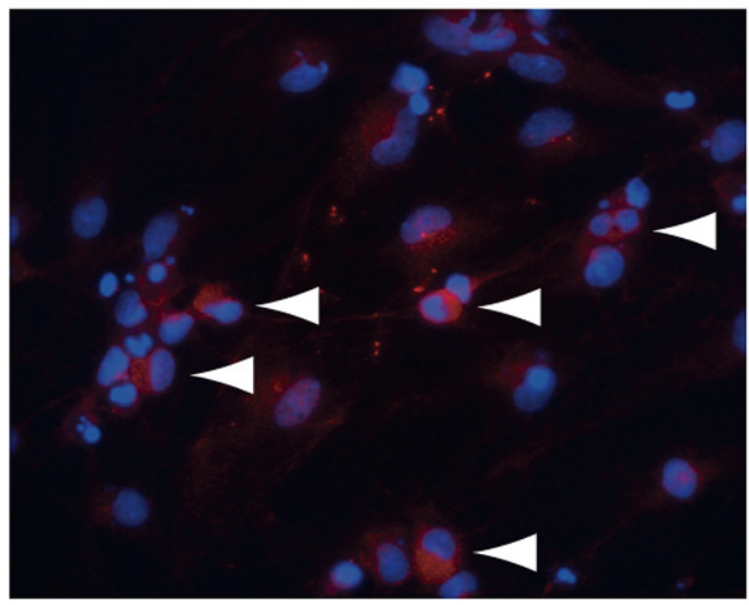

B $\quad G+I, 5$ min

$\mathrm{G}+\mathrm{I}+\mathrm{LY}, 5 \mathrm{~min}$
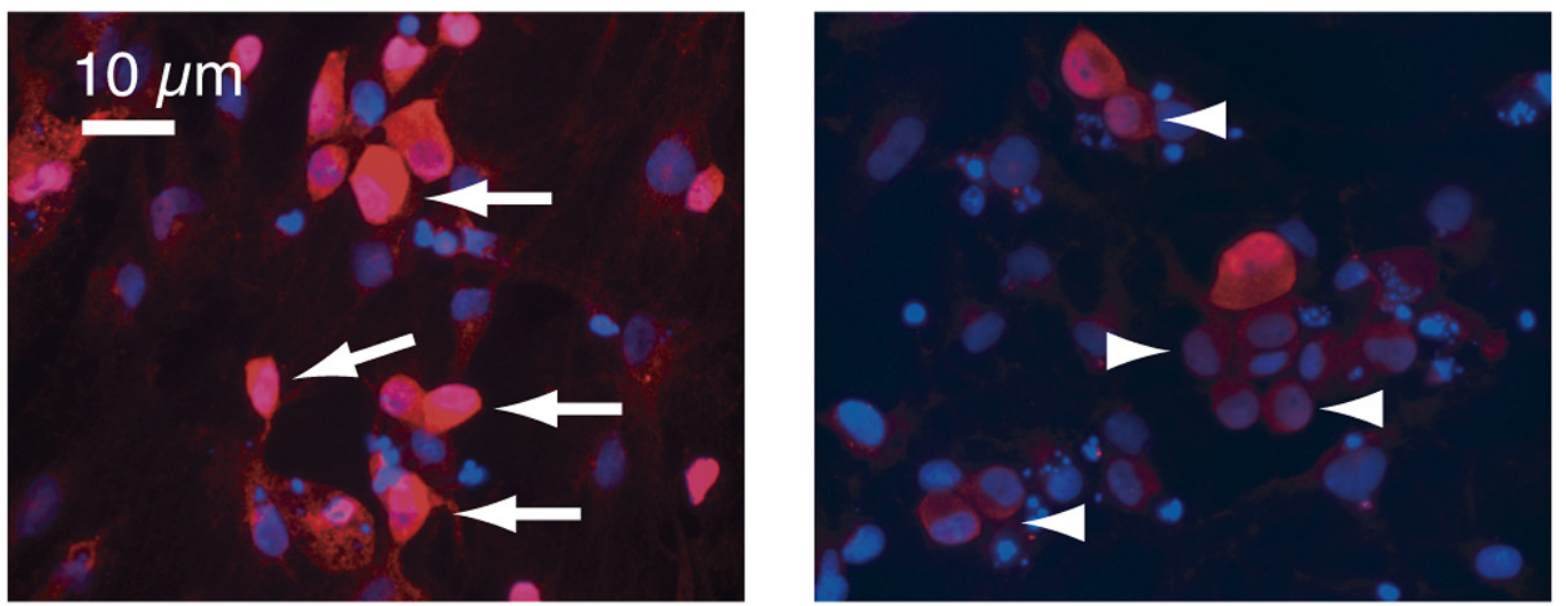
Figure 6. IGF-I causes P-FKHR to translocate out of the nuclei of DRG neurons. $\boldsymbol{A}$ ) DRG neurons were treated with IGF-I for 0, 5, 15, and 30 min and analyzed via immunocytochemistry for Phospho FKHR ser256 (red). Nuclei were labeled with Hoechst 33342 dye (blue). Control DRG neurons (C) express little p-FKHR in nuclei, with most expression being extra-nuclear. Addition of IGF-I for $5 \mathrm{~min}(\mathrm{C}+\mathrm{I}, 5 \mathrm{~min})$ produces a robust increase of p-FKHR labeling throughout DRG neurons, including in the nucleus (represented by the pink labeling caused by the overlay of red and blue labels, arrows). By $15 \mathrm{~min}$ of IGF-I treatment (C+I, $15 \mathrm{~min}$ ), this nuclear p-FKHR localization is diminishing, and takes on a more punctate appearance (pink, arrowheads). After 30 min of IGF-I treatment (C+I, $30 \mathrm{~min}$ ), p-FKHR is localized in the extra-nuclear regions of the DRG neuronal cell bodies but not within nuclei (arrowheads), suggesting that p-FKHR has been exported from the nuclei. B) DRG neurons were treated for 5 min with high glucose $+10 \mathrm{nM}$ IGF-I (G+I, $5 \mathrm{~min})$ or glucose + IGF + $20 \mu \mathrm{M}$ LY294002 (G+I+LY, $5 \mathrm{~min})$ and analyzed via immunocytochemistry as in (A). Addition of IGF-I causes a robust increase of p-FKHR in DRG neurons, including in the nuclei (pink labeling, arrows). However, LY294002 drastically reduces p-FKHR labeling, such that little is seen in the most cell bodies or nuclei (arrowheads). This suggests that blocking the PI3K/Akt pathway prevents IGF-I from mediating FKHR phosphorylation and export of p-FKHR from the nucleus. 
Fig. 7

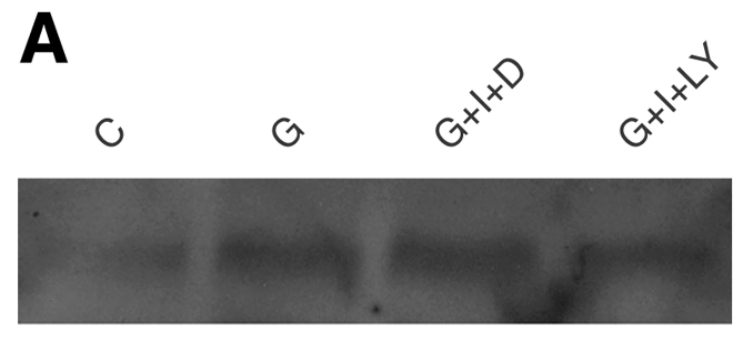

Bim

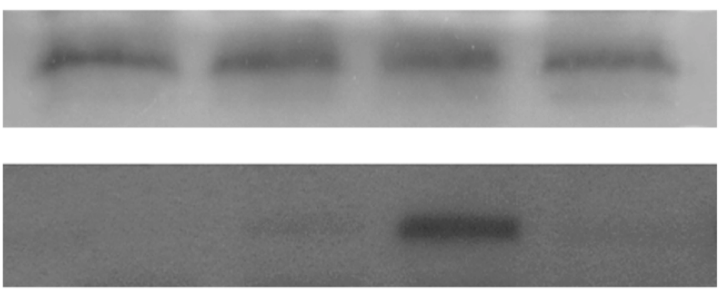

$\mathrm{BCl}-\mathrm{xL}$

pAkt

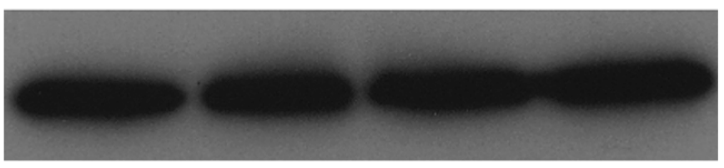

\section{GAPDH}

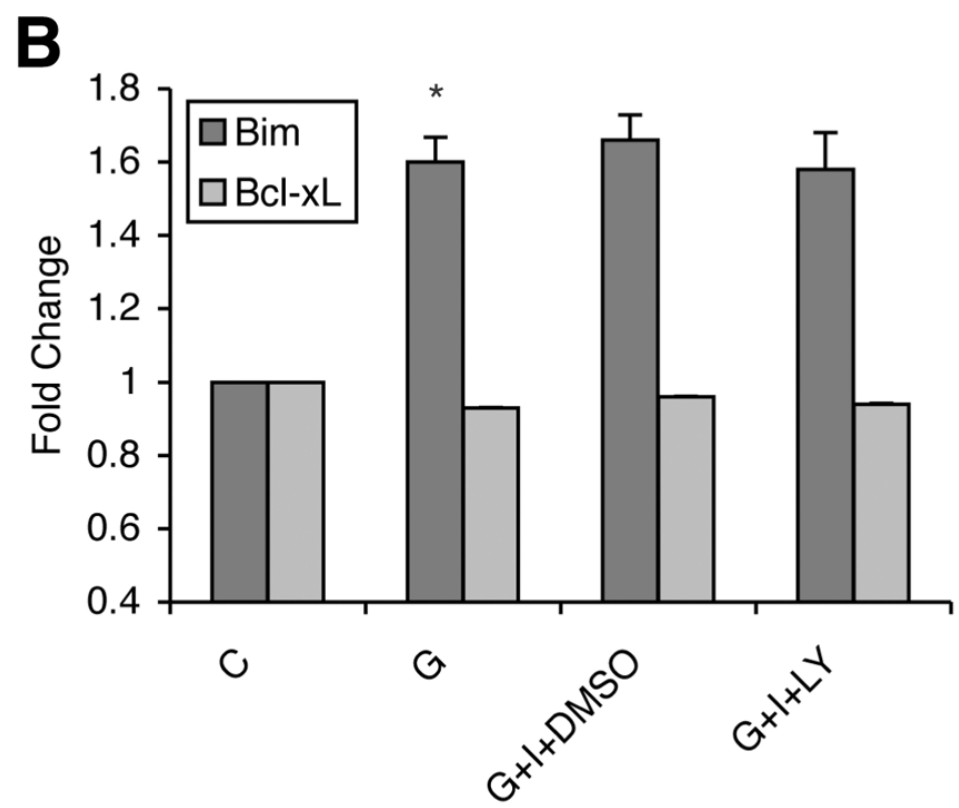

Figure 7. IGF-I does not attenuate changes in Bcl protein expression in high glucose-treated DRG neurons. $A$ ) DRG neurons were treated for $3 \mathrm{~h}$ in control media (C), glucose (G), or glucose $+10 \mathrm{nM}$ IGF-I and $0.1 \%$ DMSO (G+I+DMSO) or $20 \mu \mathrm{M}$ LY294002 (G+I+LY). Lysates were analyzed by immunoblotting. High glucose increases expression of $\mathrm{Bim}_{\mathrm{s}}$, which is not attenuated by IGF-I or by inhibiting the PI3K/Akt pathway. Bcl-xL expression is not altered by glucose, IGF-I, or inhibition of the PI3K/Akt pathway by LY294002. These null effects are not attributable to faulty PI3K/Akt signaling, as IGF-I causes phosphorylation of Akt (pAkt) and this is inhibited by LY294002. Protein loading is equal between samples, as shown by the GAPDH immunoblot. Immunoblots shown are representative of results from three separate experiments. $\boldsymbol{B})$ Densitometry of immunoblot experiments described in $(\boldsymbol{A})$. Graphed data represents fold expression of each sample as compared to control (C). Error bars represent the standard error of the mean (SEM). The fold change in Bim between control and high glucose treatments is significant $(* P<0.05)$ as determined by one-way ANOVA. 
Fig. 8

A

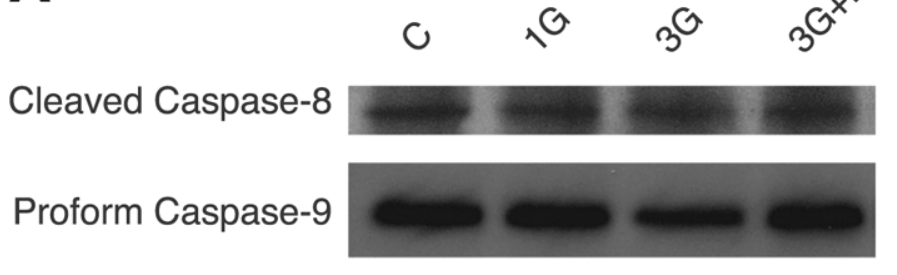

Cleaved Caspase-3

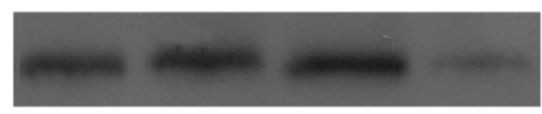

\section{GAPDH}

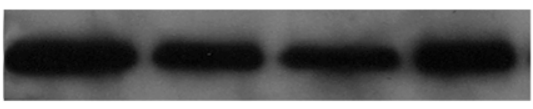

C

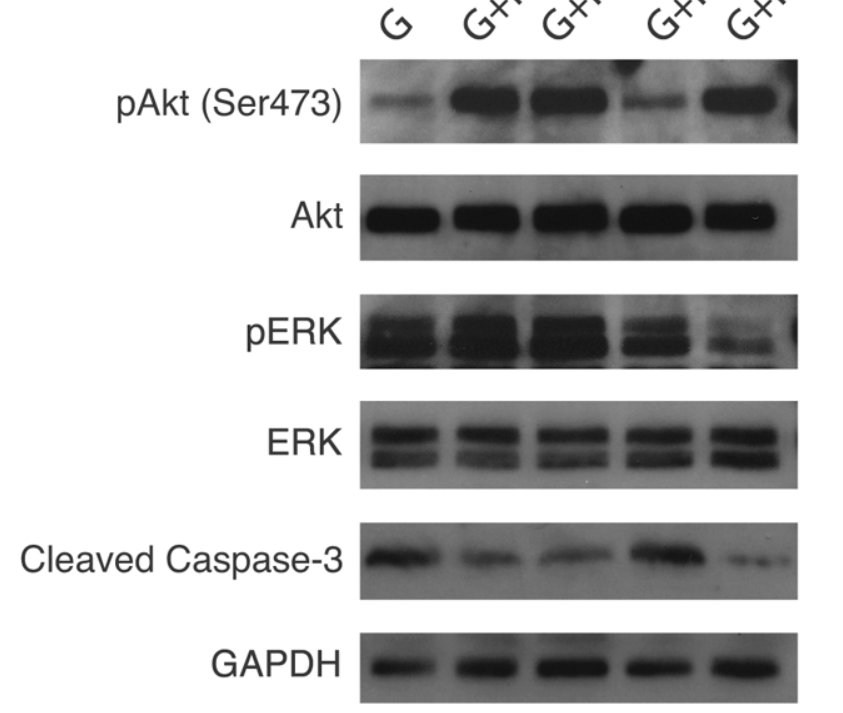

B

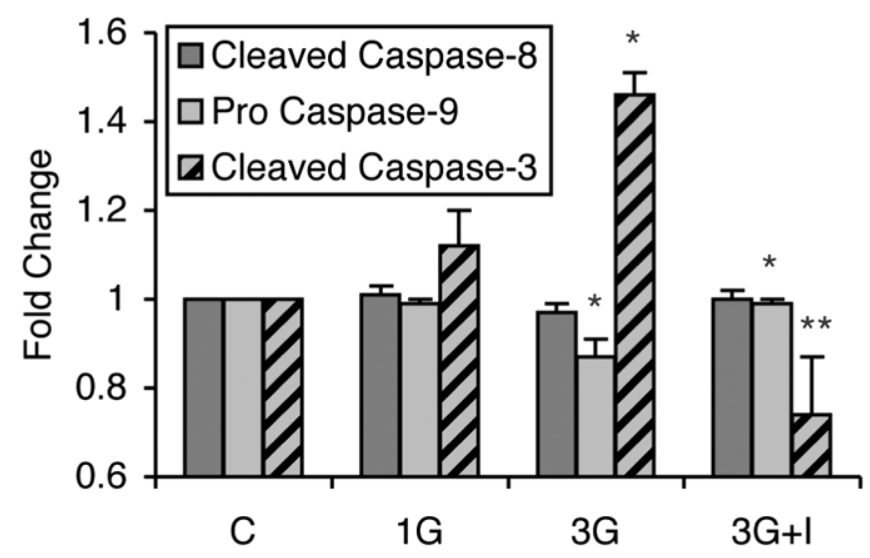

D

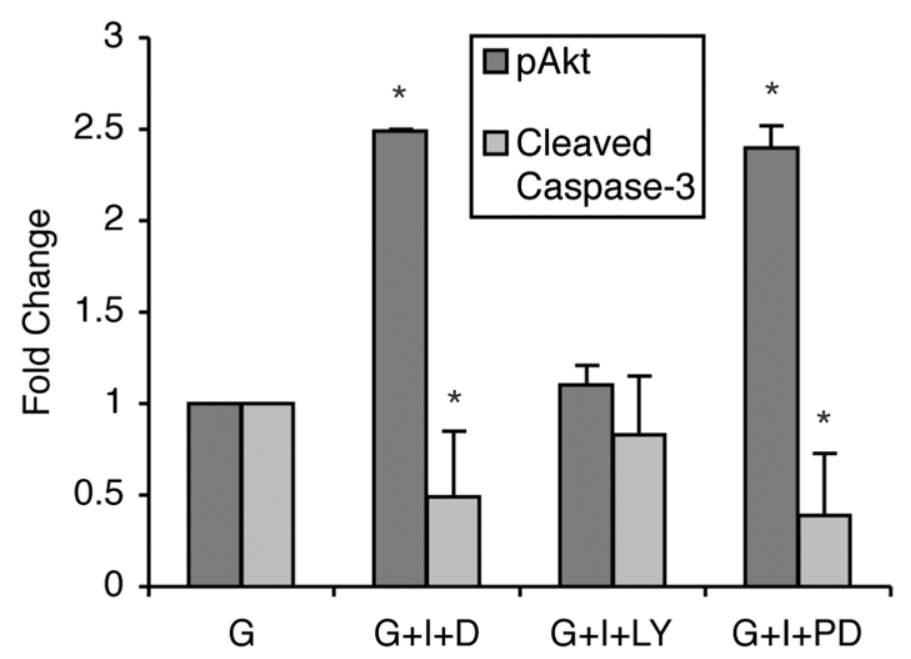

Figure 8. IGF-I inhibits caspases through the PI3K/Akt pathway. $\boldsymbol{A}$ ) DRG neurons were treated in control media (C), or with glucose for $1 \mathrm{~h}(1 \mathrm{G})$, glucose for $3 \mathrm{~h}(3 \mathrm{G})$ or glucose $+10 \mathrm{nM}$ IGF-I for $3 \mathrm{~h}(3 \mathrm{G}+\mathrm{I})$. Protein lysates were collected and analyzed via immunoblotting. High glucose treatment does not increase caspase- 8 cleavage in DRG neurons (43 kDa cleavage band), but does decrease proform caspase-9 levels after 3h. IGF-I inhibits the loss of caspase-9 proform. IGF-I also inhibits high glucose-induced caspase-3 cleavage. The GADPH immunoblot demonstrates equal protein loading between samples. $\boldsymbol{B})$ Densitometry of immunoblot experiments described in $(\boldsymbol{A})$. Graphed data represents fold expression of each sample as compared with control (C). Error bars represent the standard error of the mean (SEM). Significant differences are indicated by $* P<0.05$ and $* * P<0.01$ as determined by one-way ANOVA. $C$ ) DRG neurons were treated for $3 \mathrm{~h}$ with glucose $(\mathrm{G})$, glucose $+10 \mathrm{nM}$ IGF-I $(\mathrm{G}+\mathrm{I})$, or glucose $+10 \mathrm{nM}$ IGF-I and $0.1 \%$ DMSO $(\mathrm{G}+\mathrm{I}+\mathrm{D}), 20 \mu \mathrm{M}$ LY294002 (G+I+LY) or PD98059 inhibitors (G+I+PD). Protein lysates were analyzed via immunoblotting. LY294002 inhibits IGF-I activation of Akt (pAkt) in DRG neurons but total Akt levels are equivalent. PD98059 inhibits ERK phosphorylation (pERK) in DRG neurons, but does not alter total ERK levels. Caspase-3 cleavage is inhibited by IGF-I, but addition of LY294002 increases caspase-3 cleavage to similar levels as DRG neurons treated with glucose alone (G+I+LY vs. G). However, PD98059 does not inhibit IGF-I inhibition of caspase-3 cleavage. The GAPDH immunoblot confirms equal protein loading between samples. Immunoblots shown are representative of results from three separate experiments. $\boldsymbol{D})$ Densitometry of phosphorylated Akt (pAkt) and cleaved caspase-3 from the immunoblot experiments described in $(\boldsymbol{C})$. Graphed data represents fold expression of each sample as compared to the $3 \mathrm{~h}$ high glucose sample (G). Error bars represent the standard error of the mean (SEM). Significant differences are indicated by $* P<0.05$ as determined by one-way ANOVA. 